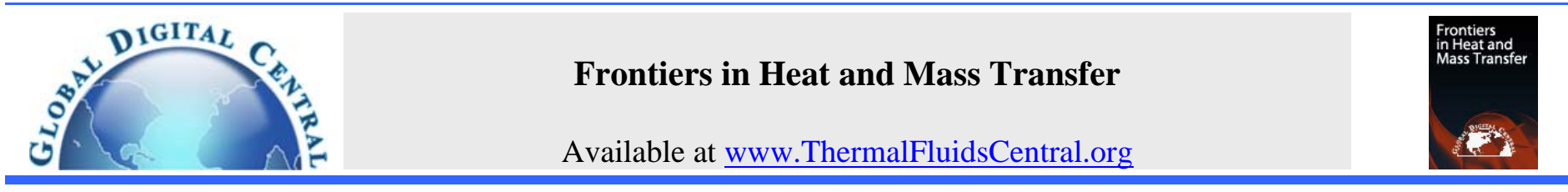

\title{
NUMERICAL INVESTIGATIONS ON HEAT TRANSFER AND FLOW STRUCTURE IN A CIRCULAR TUBE WITH VARIOUS SHAPES OF WINGLET VORTEX GENERATORS
}

\author{
Amnart Boonloi ${ }^{\mathrm{a}}$ and Withada Jedsadaratanachai ${ }^{\mathrm{b}, *}$ \\ ${ }^{a}$ Department of Mechanical Engineering Technology, College of Industrial Technology, King Mongkut's University of Technology North Bangkok, \\ Bangkok 10800, Thailand \\ ${ }^{b}$ Department of Mechanical Engineering, Faculty of Engineering, King Mongkut's Institute of Technology Ladkrabang, Bangkok 10520, Thailand
}

\begin{abstract}
The numerical investigations on flow structure, heat transfer characteristic and thermal performance in a circular tube heat exchanger with various shapes of winglet vortex generators are reported. The rectangular winglet vortex generators $(R W V G)$, delta winglet vortex generators $(D W V G)$ and curve winglet vortex generators $(C W V G)$ are inserted in the middle of the test tube on both downstream and upstream arrangements. The effects of blockage ratios; $B R=0.1-0.3$, with single pitch ratio $(P R=1)$ and flow attack angle $\left(\alpha=30^{\circ}\right)$ on thermal performance are studied for the Reynolds numbers; $R e=100-2000$. The numerical results are presented in terms of flow and heat transfer patterns; tangential velocity vectors, temperature distributions, local Nusselt number distributions, and compared with the smooth tube. As the results, it is found that the use of the winglets performs higher heat transfer rate, friction factor and thermal performance higher than the smooth tube for all cases. The rise of $B R$ and $R e$ leads to enhance on both the heat transfer rate and friction loss due to the stronger vortex flow. The RWVG provides the highest heat transfer rate and friction loss, while the $D W V G$ gives the reversed result. The downstream arrangement produces higher heat transfer rate than the upstream. In addition, the thermal enhancement factor is found to be maximum at $B R=0.2, R e=1000$, for $R W V G$ with pointing downstream around 2.52 .
\end{abstract}

Keywords: Rectangular winglet; Delta winglet; Curve winglet; Thermal performance; Numerical investigation.

\section{INTRODUCTION}

Winglet is a type of the vortex generator, which always use in the tube or channel heat exchanger to augment the heat transfer rate and thermal performance. The winglet can improve the heat transfer rate and performance by creating the vortex flow, swirling flow and impinging flow in the tube. The difference of the winglet geometry may lead to variations of the flow and heat transfer behavior. It is necessary to understand the mechanism in the heat exchanger that installed with the winglet vortex generators. The understanding of flow and heat transfer profiles is a way to develop the new design of the compact heat exchanger. The investigations on flow and heat transfer in the tube heat exchanger had been reported by many researchers on both numerical and experimental methods.

For examples, Min and Zhang (2014) numerically investigated on flow configuration and mass transfer in a membrane channel with rectangular winglets for the Reynolds number, $R e=400-1000$. They used the rectangular winglets as longitudinal vortex generators to enhance the heat transfer rate. Gholami et al. (2014) studied the heat transfer improvement in a fin-and-tube heat exchanger with $30^{\circ}$ wavy rectangular winglet vortex generators; wavy-up and wavy-down, by using an experimental method for the Reynolds number, $R e=400-800$. They stated that the wavy rectangular winglet vortex generators can augment heat transfer rate with a moderate pressure loss penalty, especially, wavy-up case. Chokphoemphun et al. (2015) experimentally investigated a tube heat exchanger inserted with $30^{\circ}$ winglet vortex generators on heat transfer and pressure loss for turbulent regime, $R e=$ $5300-24,000$. The effects of pitch ratios and blockage ratios for the winglet vortex generators were reported. They stated that use of the winglet vortex generators gives the Nusselt number around 2.03- 2.34 times higher than the smooth tube. They also claimed that the tube inserted with the winglet vortex generators performs higher thermal performance than the use of wire coil and twisted tape. Caliskan (2014) studied the heat transfer enhancement with punched triangular vortex generators (PTVGs) and punched rectangular vortex generators (PRVGs) in an $A R=2$ rectangular channel. The effects of the flow attack angles; $15^{\circ}, 45^{\circ}$ and $70^{\circ}$ with single transverse pitch ratio and blockage ratio were presented for $R e=3288-37,817$. Caliskan (2014) reported that the $P T V G$ produces the best heat transfer performance and the augmentation of heat transfer rate is around $23-55 \%$. Saha et al. (2014) reported the performance assessment in a plate-fin heat exchanger with winglet type vortex generators. The rectangular winglet pair $(R W P)$ and the delta winglet pair (DWP) with common-flow-up and common-flow-down arrangements were studied. They concluded that the strong secondary flow, which created by vortex generators, helps to a better fluid mixing and enhancing heat transfer rate. They also stated that the RWP gives higher heat transfer rate than the DWP. Wang et al. (2015) presented the use of novel longitudinal vortex generators in a fin-and-tube heat exchanger to improve thermal performance. They combined between rectangular wing and trapezoidal wing as the new type of the vortex generators. They indicated that the use of the new type vortex generators gives the heat transfer rate and pressure loss around $1.8-24.2 \%$ and 1.3 $-29.1 \%$, respectively, when compared with the base case. Li et al. (2015) numerically investigated the flow structure and heat transfer behavior in a fin-and-tube heat exchanger with longitudinal vortex generators; rectangular and delta winglets. As their results, the rectangular winglet provides higher heat transfer rate than the delta winglet. They concluded that the best thermal performance is found at the flow attack angle of $25^{\circ}$ and $45^{\circ}$ for the rectangular winglet and delta winglet, respectively. Delac

*Corresponding author. Email: kjwithad@kmitl.ac.th 
et al. (2014) numerically studied heat transfer improvement in a fin-andtube heat exchanger with downstream rectangular winglet vortex generators. The influences of the flow attack angles; $5^{\circ}, 10^{\circ}$ and $20^{\circ}$, for the winglet vortex generators were studied for $R e=350-2200$. They presented that the high values of flow attack angle and winglet high perform enlarge pressure loss. Hsiao et al. (2014) reported the investigations on flow and heat transfer behaviors a micro-channel heat exchanger with rectangular winglet pairs. They found that the rectangular winglet provides a better fluid mixing by generating longitudinal vortices through the test channel. Zdanski et al. (2015) studied the effects of delta winglet vortex generators on the flow topology and heat transfer rate of air over an in-line tube bank with experimental method. They found that the maximum heat transfer rate is higher than the base case around $30 \%$, while the pressure loss increases around 40\%. Lin et al. (2015) numerically investigated a fin-and-tube heat exchanger with curved delta winglet vortex generators ( $C D W V G$ s) on flow structure and heat transfer characteristic. They indicated that the CDWVG can reduce the size of wake zone and also produces the secondary flow over the test section. These behaviors help to enhance the heat transfer rate and thermal performance. Aliabadi et al. (2015) studied heat transfer augmentation in a tube heat exchanger with delta winglet vortex generators at various arrangements. They reported the thermal performance in term of performance evaluation criterion or PEC is around 1.41 at $R e=8715$. Hatami et al. (2015) presented the new design of heat exchanger to recover exergy from the exhaust of diesel engine by using delta winglet vortex generators. Wang et al. (2015) numerically analyzed the pressure loss and heat transfer improvement in a channel with delta winglets. They claimed that the maximum $j$-factor and $f$-factor increase around $24.96 \%$ and $17.61 \%$, respectively. Du et al. (2014) presented the heat transfer enhancement in a fin-and-tube heat exchanger with $25^{\circ}$ punched delta winglet pairs. They stated that the optimum PEC is around 1.23 when using the $25^{\circ}$ punched delta winglet pairs. Zhou and Feng (2014) experimentally investigated the heat transfer augmentation in heat exchanger with plane and curved winglet vortex generators. The influences of the three differences winglet shapes; rectangular, trapezoidal and delta, with and without punching holes were reported. They found that the curved winglet provides higher heat transfer rate and lower friction loss than plane winglet for all shapes on both laminar and turbulent regimes. Gong et al. (2015) studied the heat transfer characteristic in a fin-and-tube heat exchanger with punched curve rectangular vortex generators (CRVGs). They found that the use of $C R V G$ provides higher heat transfer rate than the plain fin due to secondary flow and small size of wake regime. Lofti et al. (2014a) and Lofti et al. (2014b) numerically investigated in three dimensions on flow structure and heat transfer characteristic for a fin-and-tube heat exchanger with new type vortex generators; rectangular trapezoidal winglet (RTW), angle rectangular winglet $(A R W)$, curved angle rectangular winglet $(C A R W)$ and wheeler wishbone $(W W)$. The influences of the flow attack angles; $15^{\circ}, 30^{\circ}, 45^{\circ}, 60^{\circ}$ and $75^{\circ}$, were studied. They concluded that the CARW performs the best thermal performance at a small attack angle, while the $R T W$ gives the optimal thermal performance at a large attack angle.

In the current work, the numerical investigation is selected to study the flow configuration, heat transfer characteristics and thermal performance in the circular tube with various shape winglet vortex generators due to the numerical result can describe the mechanism in the test tube. The three types of the winglet; rectangular winglet vortex generators $(R W V G)$, delta winglet vortex generators ( $D W V G)$ and curve winglet vortex generators $(C W V G)$ with single pitch spacing ratio $(P R=$ 1 ) and flow attack angle $\left(\alpha=30^{\circ}\right)$ are compared on flow structure and heat transfer characteristic for laminar regime, $R e=100-2000$. The numerical results are presented in forms of tangential velocity vectors, temperature distributions, local Nusselt number distributions and performance evaluations. The empirical correlations on both Nusselt number ratio and friction factor ratio for the circular tube heat exchanger with the $R W V G, D W V G$ and $C W V G$ are also reported.

\section{BOUNDARY CONDITION AND ASSUMPTION}

\subsection{Boundary condition}

The boundary conditions of the circular tube heat exchanger with various winglet vortex generators are as follows:

Inlet and outlet of the computational domain for the circular tube with winglet vortex generators are set as periodic condition.

The air with $300 \mathrm{~K}(\mathrm{Pr}=0.7)$ with a constant mass flow rate is assumed in the flow direction rather than constant pressure drop due to periodic flow conditions.

The properties of the test fluid are assumed to remain constant at average bulk temperature.

- Impermeable boundary and no-slip wall conditions are implemented over the tube wall as well as the winglet vortex generators.

- The constant temperature of the circular tube wall is maintained at $310 \mathrm{~K}$ while the winglet and smooth plate are assumed as adiabatic wall conditions.

\subsection{Assumption}

The numerical model for the fluid flow and heat transfer in the circular tube is developed under the following assumptions:

- $\quad$ Steady three-dimensional fluid flow and heat transfer.

- $\quad$ The flow is laminar and incompressible.

- $\quad$ Constant fluid properties.

- $\quad$ Body forces and viscous dissipation are ignored.

- $\quad$ Negligible radiation heat transfer.

\section{MATHEMATICAL FOUNDATION}

Based on the above assumptions, the flow in circular tube is governed by the continuity, the Navier-Stokes and the energy equations. In the Cartesian tensor system these equations can be written as follows: Continuity equation:

$\frac{\partial}{\partial \mathrm{x}_{\mathrm{i}}}\left(\rho \mathrm{u}_{\mathrm{i}}\right)=0$

Momentum equation:

$\frac{\partial\left(\rho u_{i} u_{j}\right)}{\partial x_{j}}=-\frac{\partial p}{\partial x_{i}}+\frac{\partial}{\partial x_{j}}\left[\mu\left(\frac{\partial u_{i}}{\partial x_{j}}+\frac{\partial u_{j}}{\partial x_{i}}\right)\right]$

Energy equation:

$\frac{\partial\left(\rho u_{i} T\right)}{\partial x_{i}}=\frac{\partial}{\partial x_{j}}\left(\Gamma \frac{\partial T}{\partial x_{j}}\right)$

where, $\Gamma$ is the thermal diffusivity and is given by

$\Gamma=\frac{\mu}{\operatorname{Pr}}$

Apart from the energy equation discretize by the QUICK scheme, the governing equations are discretized by the second order upwind (SOU) scheme, decoupling with the SIMPLE algorithm, and solved by using a finite volume approach (Patankar, 1980). The solutions were considered to be converged when the normalized residual values were less than $10^{-5}$ for all variables, but less than $10^{-9}$ only for the energy equation.

Four parameters of interest in the present work are the Reynolds number, friction factor, Nusselt number and thermal enhancement factor. The Reynolds number is defined as

$\operatorname{Re}=\rho \bar{u} D / \mu$

The friction factor, $f$ is computed by pressure drop, $\Delta p$, across the length of the periodic tube, $\mathrm{L}$, as

$f=\frac{(\Delta p / L) D}{\frac{1}{2} \rho \bar{u}^{2}}$

The heat transfer is measured by local Nusselt number which can be written as 


$$
N u_{x}=\frac{h_{x} D}{k}
$$

The average Nusselt number can be obtained by

$$
N u=\frac{1}{L} \int N u_{x} \partial x
$$

The thermal enhancement factor (TEF) is defined as the ratio of the heat transfer coefficient of an augmented surface, $h$ to that of a smooth surface, $h_{0}$, at an equal pumping power and given by

$T E F=\left.\frac{h}{h_{0}}\right|_{p p}=\left.\frac{N u}{N u_{0}}\right|_{p p}=\left(N u / N u_{0}\right) /\left(f / f_{0}\right)^{1 / 3}$

where $N u_{0}$ and $f_{0}$ stand for Nusselt number and friction factor for the smooth tube, respectively.

\section{TUBE CONFIGURATION AND COMPUTATIONAL DOMAIN}

Figs. 1, 2 and 3 present $R W V G, D W V G$ and $C W V G$, which are punched out from the thin-smooth plates (plate width $=D$ ), at $B R=0.2$. The tube diameter, $D$, is equal to $0.05 \mathrm{~m}$. The $R W V G, D W V G$ and $C W V G$ are inserted in the middle of the circular tube on both downstream and upstream arrangements as depicted in the Figs. $4 a, b$ and $c$, respectively. The influences of the blockage ratios, $b / D$ or $B R=0.1,0.2$ and 0.3 with a single pitch spacing ratio, $L / D$ or $P R=1$, and flow attack angle of $30^{\circ}$ are investigated numerically in three dimensions for $R e=100-2000$. The details of winglet parameters are reported as the Figs. $5 a, b$ and $c$ for $R W V G, D W V G$ and $C W V G$, respectively. The $R W V G$ with surface mesh is depicted in Fig. 5d.

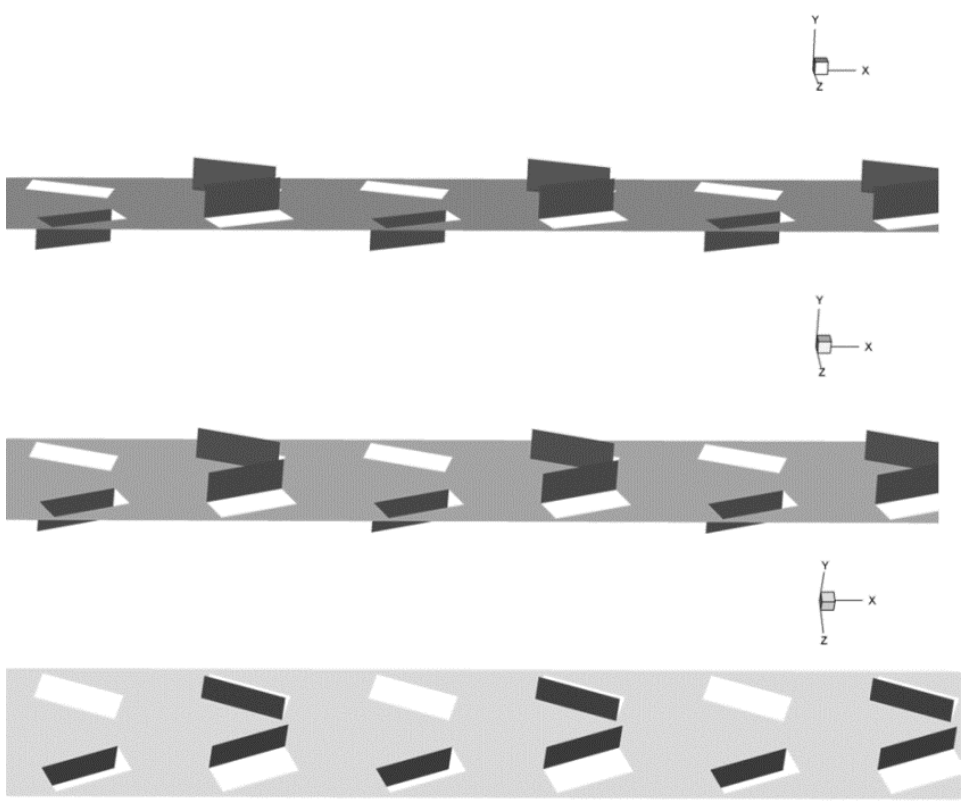

Fig. 1 Rectangular winglet vortex generators, $R W V G$.

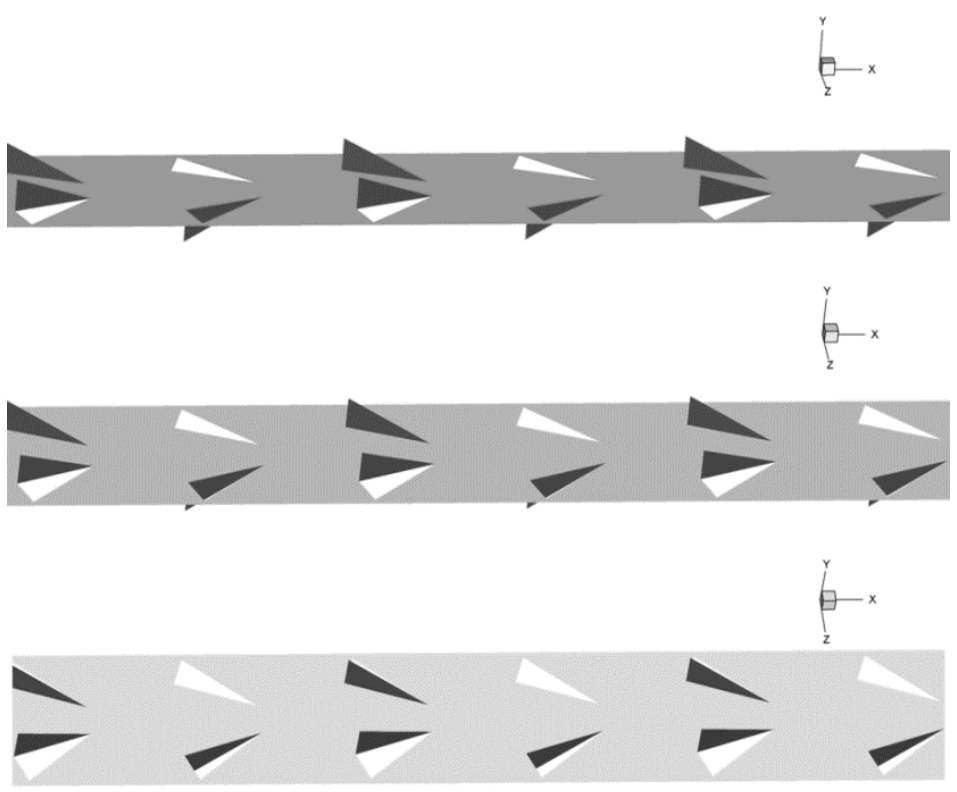

Fig. 2 Delta winglet vortex generators, DWVG. 


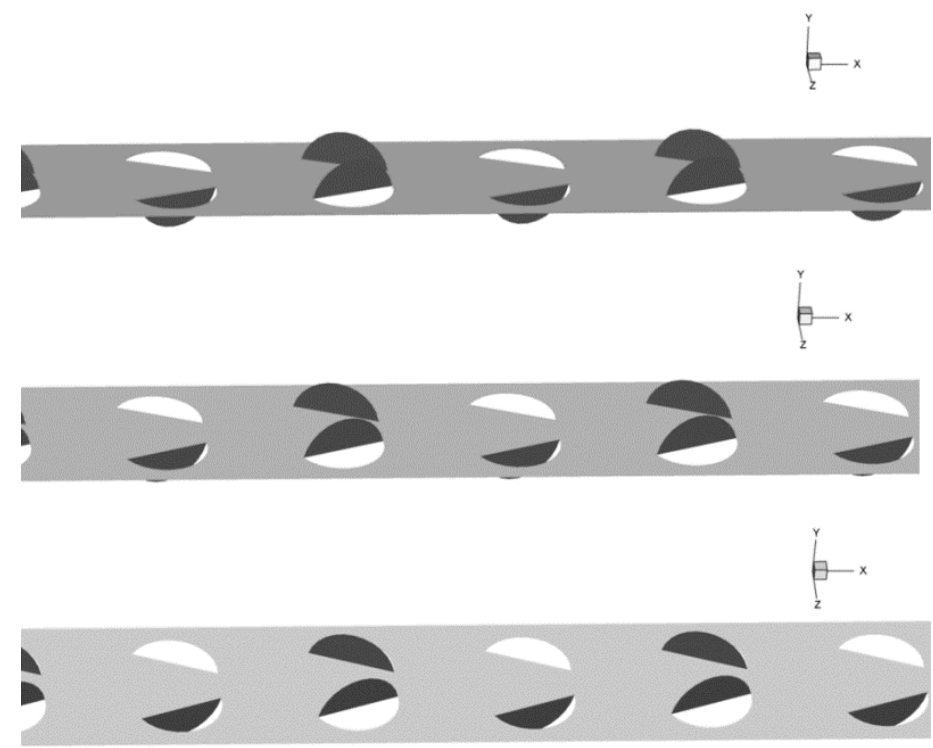

Fig. 3 Curve winglet vortex generators, CWVG.

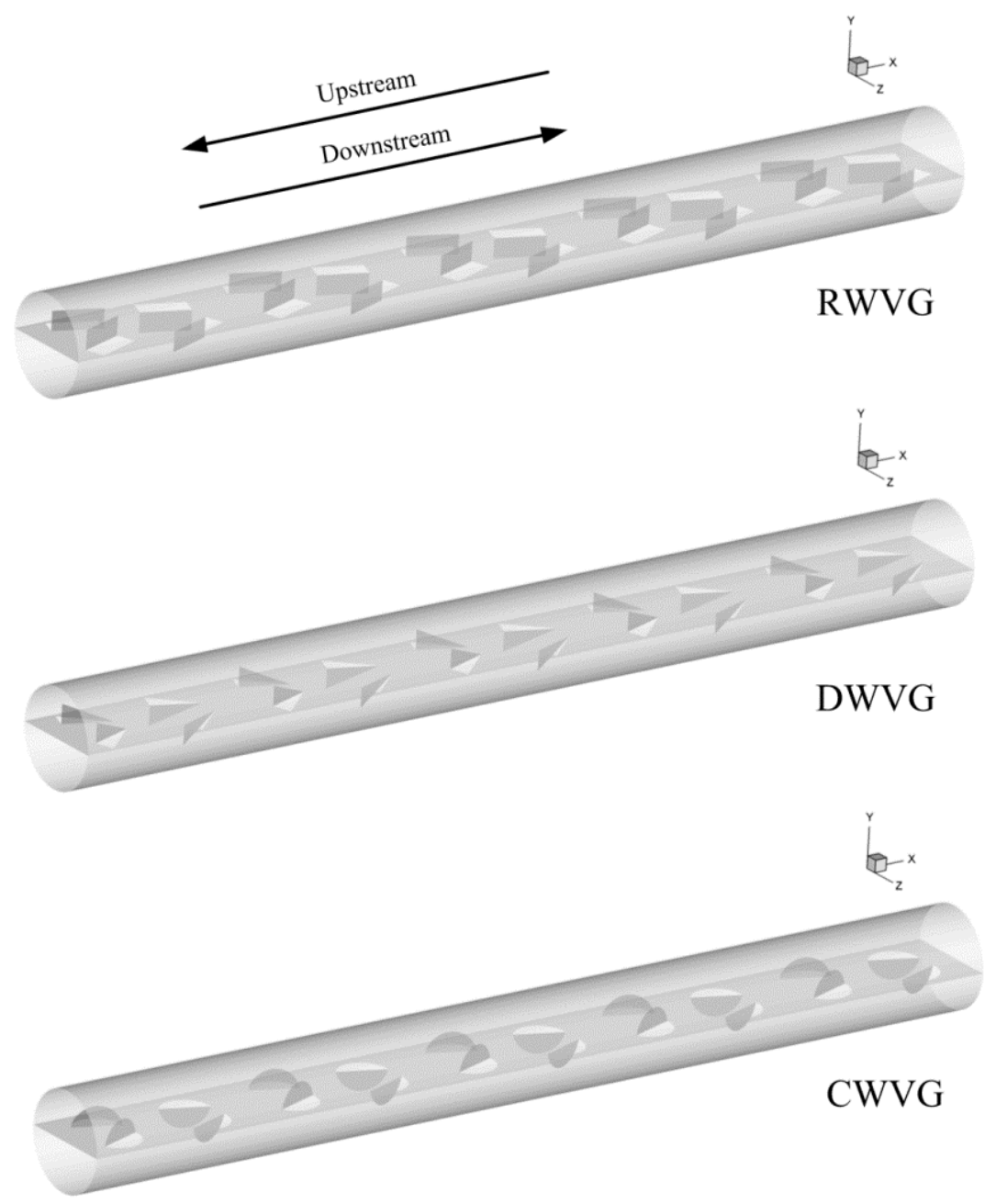

Fig. 4 Circular tubes with $R W V G, D W V G$ and $C W V G$ inserted in the middle of the tube. 


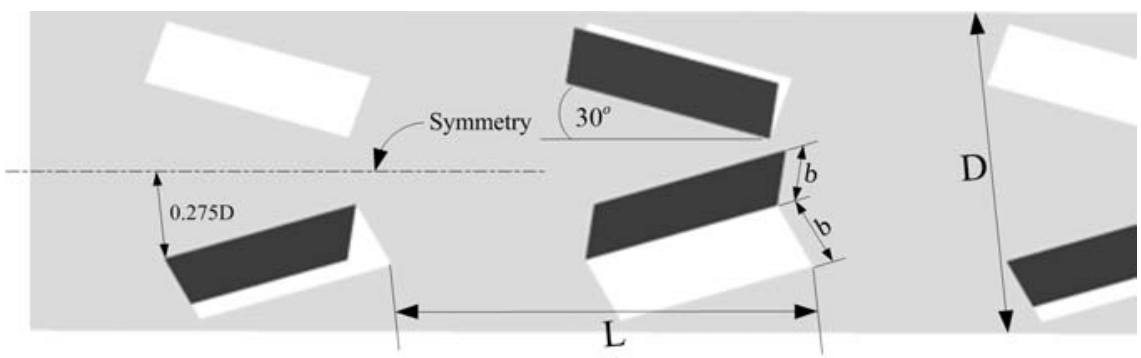

(a)

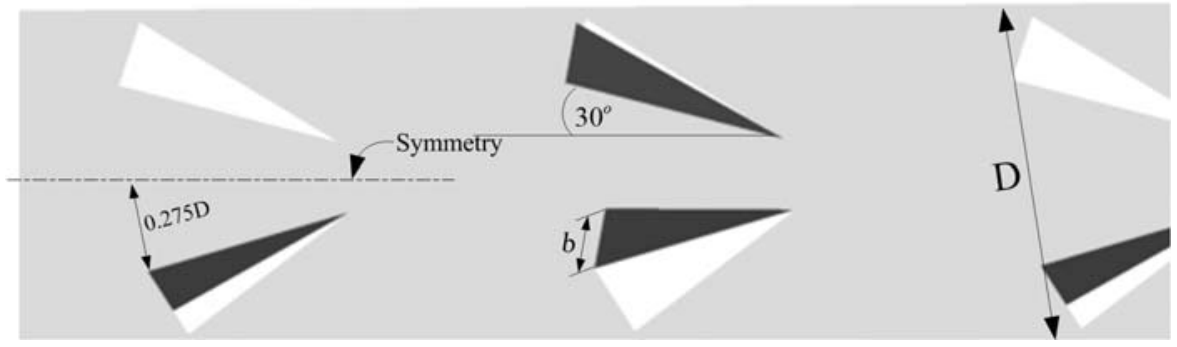

(b)

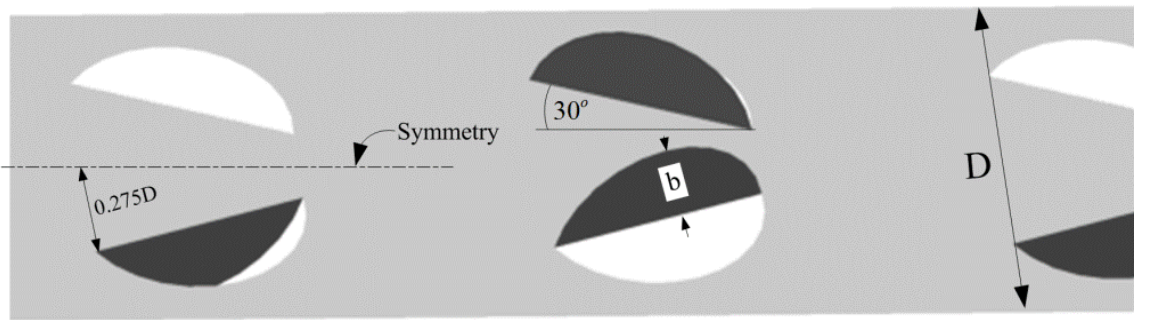

(c)

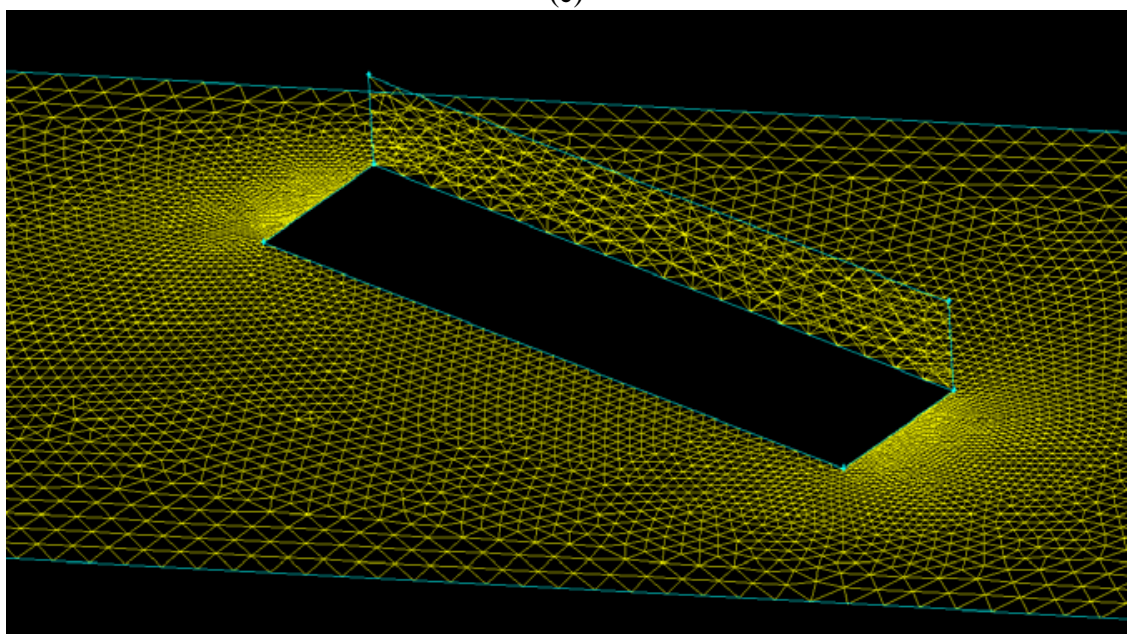

Fig. 5 Parameters of the (a) RWVG, (b) DWVG, (c) CWVG and (d) mesh of the RWVG plate.

\section{NUMERICAL RESULTS AND DISCUSSION}

\subsection{Numerical results}

The numerical results are divided into four parts; validation of the computational domain, flow structure, heat transfer characteristic and thermal performance evaluation. The flow and heat transfer profiles may help to describe the mechanism, which occurs in the tube heat exchanger that inserted with various winglets. The understanding on both flow and heat transfer behavior is a way to improve heat transfer rate and thermal performance in the test tube. The performance evaluation is separated into three parts; heat transfer, pressure loss and thermal enhancement factor.

\subsubsection{Validation with the smooth tube and grid independence}

It must be sure that the computational domain is reliable to predict the flow configuration and heat transfer characteristics, which occurs in the circular tube heat exchanger. The verifications of the domain can be divided into two parts; verification of the smooth tube and grid independence.

The verifications of the smooth circular tube with no generators are done by compared between the present results with the values from the correlations (Incropera and Dewitt, 2006) on both heat transfer and pressure loss in terms of the Nusselt number $(\mathrm{Nu})$ and friction factor $(f)$, respectively. Figs. $6 a$ and $b$ present the verifications of the smooth tube for the Nusselt number and friction factor, respectively. As the figures, the values on both the Nusselt number and friction loss are found in excellent agreement within $\pm 0.05 \%$ and $0.03 \%$, deviations, respectively. 
Therefore, the current computational domain is reliable to calculate the heat transfer and flow structure in the tube heat exchanger.

The grid independence is tested by comparison four sets of grid cells. The number of grid cells: 120000, 180000, 240000 and 320000, are applied to the computational domain for the circular tube heat exchanger at all types of the winglets: $R W V G, D W V G$ and $C W V G$ at $B R$ $=0.20, R e=1000$ and downstream. As the numerical results, the increasing grid cells from 180,000 to 240,000 give the Nusselt number and friction factor around $\pm 0.15 \%$ and $\pm 0.22 \%$, deviation, respectively. Considering on both times for simulation and accurate results, the 180,000 cells are selected for the current investigation.

\subsubsection{Flow structure}

The understanding of the flow structure can help to find the ways to improve the heat transfer rate and thermal performance in the heating system.

The flow structure is presented in term of tangential velocity in transverse planes at various $x / D$ positions. Figs. $7 a, b$ and $c$ show the tangential velocity vectors in transverse planes for the $R W V G, D W V G$ and $C W V G$, respectively, at $B R=0.2$ and $R e=1000$ of downstream case. As the figures, there are found that all types of the $W V G$ give four main vortex flows through the test section. The symmetry vortex flows are found in the left and right parts due to the symmetry of the winglet geometry. Considering at the upper pair of the vortex flow, the downstream case performs counter-rotating flow with common-flow-up. The $R W V G$ provides the highest density of the velocity vector, while the $D W V G$ gives the reversed result.

Figs. $8 a, b$ and $c$ illustrate the tangential velocity vectors in transverse planes at various $x / D$ values for the $R W V G, D W V G$ and $C W V G$ at $B R=0.2, R e=1000$ and upstream case, respectively. The similar flow pattern as downstream is found in upstream case, but the rotational direction is in reverse (see Fig. 10). The counter rotating vortex flow with common-flow-down is found in upstream case when considering at the upper pair of the vortex flow. The $C W V G$ gives the highest density of the tangential velocity vectors, while the $D W V G$ performs the lowest values.

The details of the tangential velocity vectors in transverse planes at various $x / D$ values: $0.25,2.75,5.25,7.75$ and 10.25 , for downstream and upstream are presented in the Figs. $9 a$ and $b$, respectively. The counter rotating vortex flow and impinging flow on tube wall for both downstream and upstream cases lead to a better fluid mixing between the core of the flow and close to the wall regime. The better fluid mixing and impinging flows are keys for heat transfer augmentation and performance enhancement.

\subsubsection{Heat transfer characteristic}

The heat transfer characteristics in the tube heat exchanger with various types of winglet vortex generators are presented in forms of temperature distributions in transverse planes and local Nusselt number distributions on the tube wall.

Figs. 11a, $b$ and $c$ present the temperature distributions in transverse planes with various $x / D$ positions for $R W V G, D W V G$ and $C W V G$, respectively, at $B R=0.2, R e=1000$, downstream case. In general, for the smooth tube with no winglet vortex generators, the blue contour (cold air) is found at the center of the tube, while the red contour (hot air) is found near the wall regime. As the figures, the red layer near the tube wall is thinner when using all types of the winglet vortex generators due to better fluid mixing. The thin red layer is found at the upper and lower parts of the planes, while the left and right parts present in opposite result.

Figs. 12a, $b$ and $c$ display the temperature distributions in transverse planes of the tube heat exchanger for $R W V G, D W V G$ and $C W V G$, respectively, at $B R=0.2$, upstream and $R e=1000$. The use of the winglet vortex generators leads to better fluid mixing between the core of the tube and wall region for all cases similarly as downstream case. The thin red layer is found in the left and right parts of the planes, while the upper and lower parts show the reversed result.

The details of the temperature distributions in transverse planes for downstream and upstream are shown in the Figs. $13 a$ and $b$, respectively. There are clearly seen in the figures that the thin red layers are found at the upper-lower parts and left-right parts of the planes for downstream and upstream, respectively. The reason of this may be that the winglet with pointing downstream can create the flows, which impinge on the upper-lower parts of the tube, while the winglet with pointing upstream generates the flows that impinge on the left-right parts of the tube.

The local Nusselt number distributions on the tube wall that inserted with $R W V G, D W V G$ and $C W V G$ at $B R=0.2$, downstream and $R e=1000$ are presented in the Figs. $14 a, b$ and $c$, respectively. In general, the use of the winglet vortex generators can enhance heat transfer rate over the smooth tube with no winglet. The peaks of heat transfer regime are found at the upper and lower parts of the tube for all types of the winglet vortex generators due to the impinging flows. The $R W V G$ performs the highest heat transfer rate, while the $C W V G$ provides higher heat transfer rate than $D W V G$. In addition, the lowest heat transfer regimes are found at left and right parts of the tube heat exchanger in all cases.

Figs. 15a, $b$ and $c$ illustrate the local Nusselt number distributions on the tube wall for $R W V G, D W V G$ and $C W V G$, respectively, at $B R=$ 0.2 , upstream and $R e=1000$. The peaks of heat transfer regime are done by impinging flows, which are found in the left and right parts of the test tube. The RWVG performs the highest and largest area of heat transfer.

\subsubsection{Performance evaluation}

Performance evaluations in the tube heat exchanger with various types of the vortex generators are divided into three parts; heat transfer, pressure loss and performance. The heat transfer and pressure loss are reported in terms of the Nusselt number ratio $\left(\mathrm{Nu} / \mathrm{Nu}_{0}\right)$ and the friction factor ratio $\left(f / f_{0}\right)$, respectively, while the performance, which computed from both $\mathrm{Nu} / \mathrm{Nu}$ o and $f / f_{0}$, is presented in term of thermal enhancement factor (TEF).

Figs. $16 a$ and $b$ present the variations of the $N u / N u_{0}$ with the Reynolds number at various BRs and winglet types for downstream and upstream, respectively. Generally, the $\mathrm{Nu} / \mathrm{Nu} u_{0}$ tends to increase with the rise of the Reynolds number and $B R$ for all cases. The $R W V G$ provides the highest heat transfer rate, while the $D W V G$ gives the reversed trend on both downstream and upstream cases. For downstream, the Nusselt number is found to be around $1.5-6.2$ times, $1.3-5$ times and $1.3-5.5$ times higher than the smooth tube for $R W V G, D W V G$ and $C W V G$, respectively. For upstream, the use of $R W V G, D W V G$ and $C W V G$ gives a higher heat transfer rate over the smooth tube around $1.3-5.8$ times, $1.3-4.8$ times and $1.3-5.2$ times, respectively. The upstream case performs lower Nusselt number than the downstream case due to the weaker vortex flow.

The use of all generators not only enhance heat transfer rate, but also augment pressure loss in the test tube. The variations of the $f / f_{0}$ with the Reynolds number at various $B R$ s and winglet types are presented in the Figs. $17 a$ and $b$, respectively, for downstream and upstream. In general, the rise of $B R$ (reduced flow area) and $R e$ results in the increasing friction loss. The highest friction loss is found in case $R W V G$, while the $D W V G$ can reduce the pressure loss in the test section. The downstream performs nearly values of $f / f_{0}$ with upstream case for all types of the winglet. In range studies, the friction factor is around $3.5-1.6$ times, $3-9.5$ times and $3-13$ times higher than the smooth tube, respectively, for $R W V G$, $D W V G$ and $C W V G$.

The relations of the TEF with the Reynolds number for the tube with various types of winglet vortex generators are depicted in the Figs. 18a and b, respectively, for downstream and upstream cases. The TEF increases when increasing the Reynolds number for all cases. Almost cases give the thermal enhancement factor higher than the smooth tube with no winglet $(T E F>1)$. The maximum $T E F$ is found at $B R=0.2, R e=$ 1000 of $R W V G$ for both downstream and upstream cases around 2.52 and 2.3 , respectively. In addition, the $B R=0.1$ of $D W V G$ performs the lowest $T E F$ on both downstream and upstream cases, but it can reduce the pressure loss in the heating system.

The relations between the $N u / N u_{0}$ with $B R$ at various Reynolds numbers and flow directions are shown as the Figs. $19 a, b$ and $c$ for $R W V G, D W V G, C W V G$, respectively. In general, the $N u / N u_{0}$ increases with the rise of the $B R$ in all cases. The $B R=0.3$ performs the highest heat transfer rate, while the $B R=0.1$ gives the reversed result. The rise of the flow blockage leads to enhance vortex strength or vortex intensity. The augmentation of the vortex strength results in the improvement of heat transfer rate in the tube heat exchanger. 
Figs. 20a, $b$ and $c$ present the relations of the $f / f_{0}$ with $B R$ at various Reynolds numbers and flow directions for RWVG, DWVG and $C W V G$, respectively. The highest friction loss is found at $B R=0.3$, while the $B R$ $=0.1$ performs the lowest value. The augmentation of the $f / f_{0}$ is found to be highest in rang $0.2<B R<0.3$, especially, $R W V G$. The downstream case performs nearly values of the $f / f_{0}$ with upstream case for all types of the winglet vortex generators.
Figs. 21a, $b$ and $c$ show the relations of the TEF with $B R$ at various cases for RWVG, DWVG and $C W V G$, respectively. Almost cases, the peak of the thermal enhancement factor is found at $B R=0.2$ due to the $B R=0.2$ gives the optimum ratio between the heat transfer enhancement and friction loss expansion in the test tube.

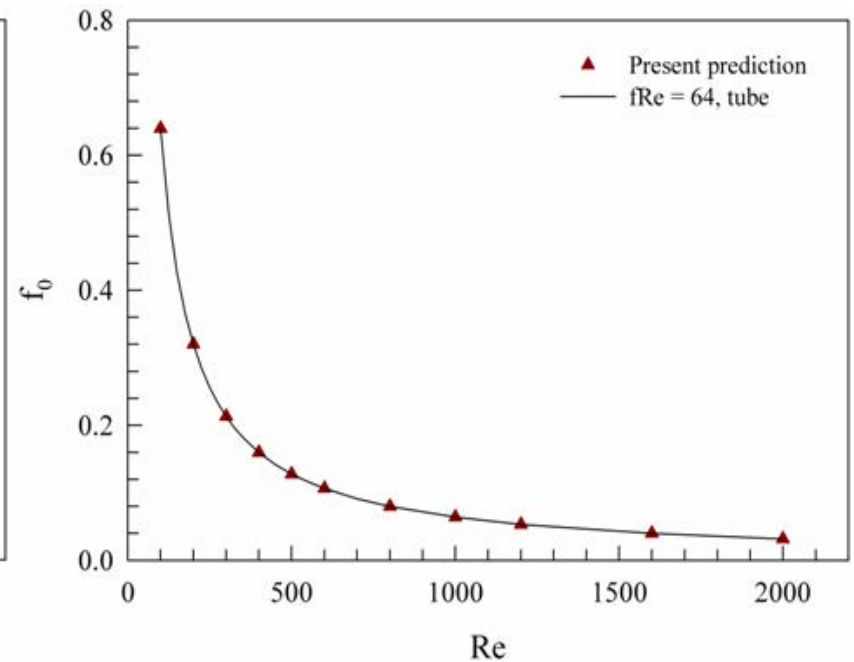

(b)

Fig. 6 Validation with the smooth tube with no winglet for (a) Nussel number and (b) friction factor.

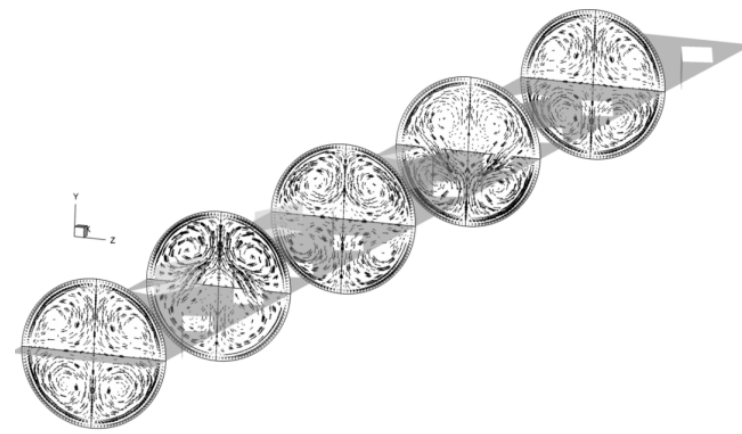

(a)

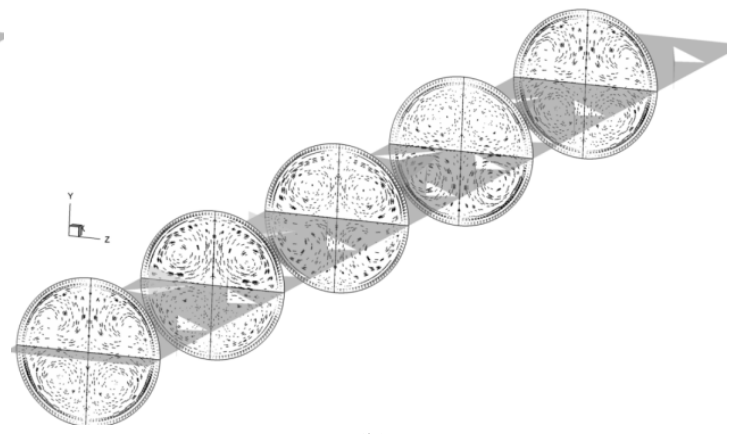

(b)

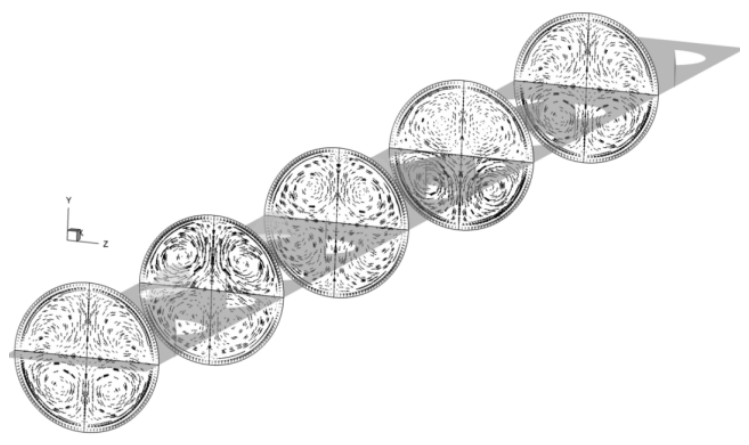

(c)

Fig. 7 Tangential velocity vectors in transverse planes for the circular tube heat exchanger of (a) $R W V G$, (b) $D W V G$ and (c) $C W V G$ at $B R=0.2, R e=$ 1000 and downstream. 


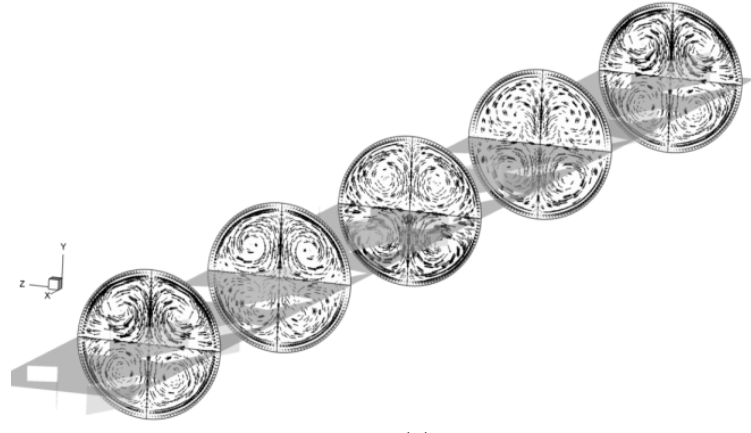

(a)

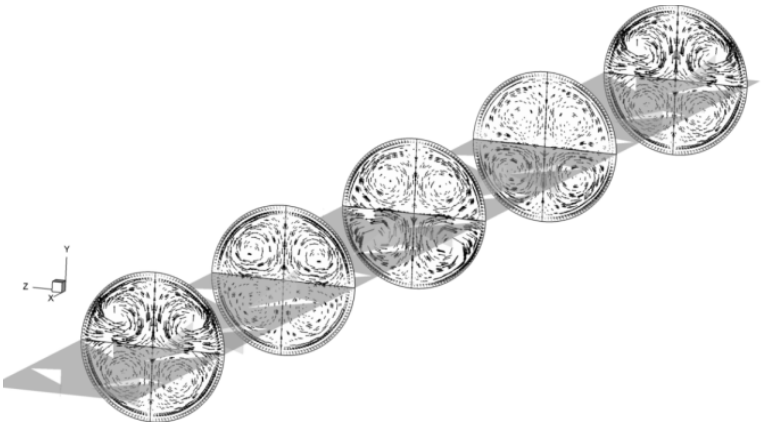

(b)

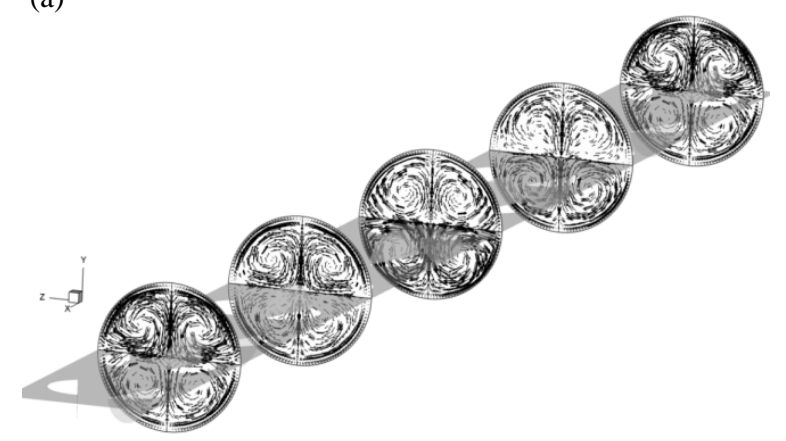

(c)

Fig. 8 Tangential velocity vectors in transverse planes for the circular tube heat exchanger of (a) $R W V G$, (b) $D W V G$ and (c) $C W V G$ at $B R=0.2, R e=$ 1000 and upstream.
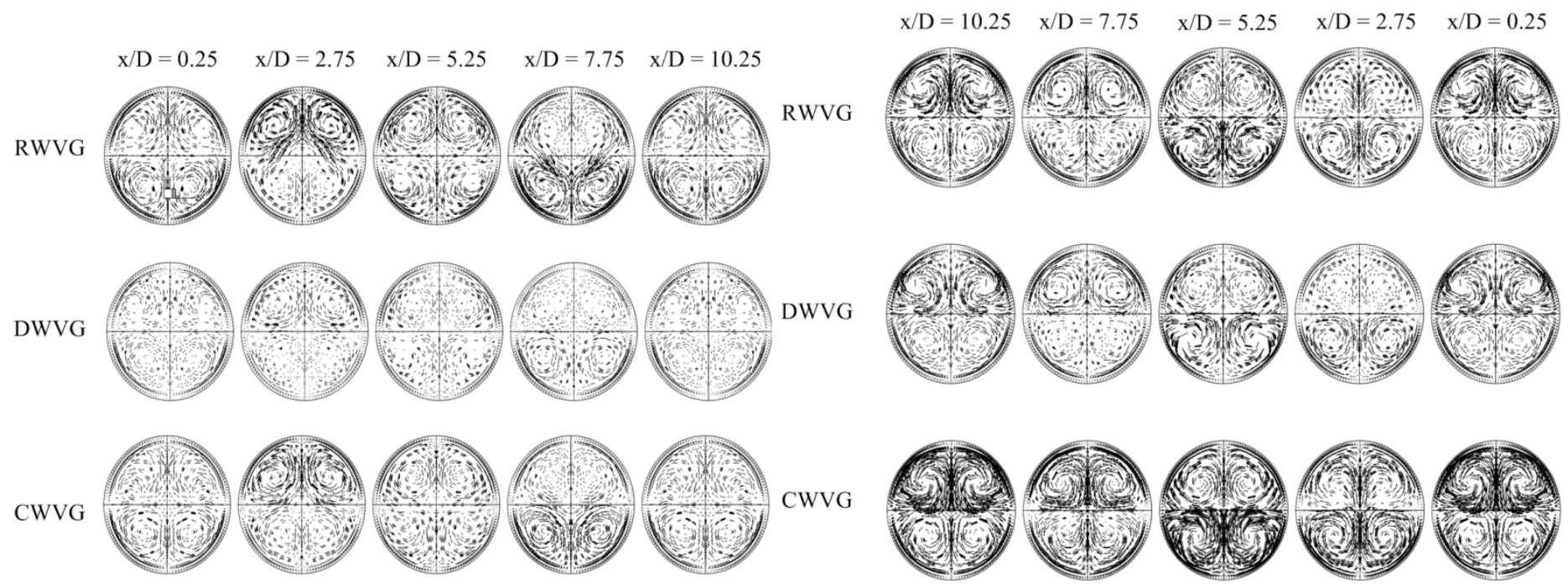

DOWNSTREAM

(a)
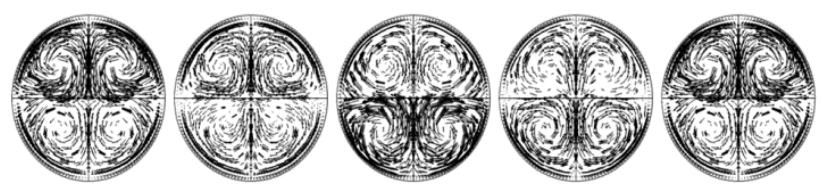

UPSTREAM

(b)

Fig. 9 Details of tangential velocity vectors in transverse planes for (a) downstream and (b) upstream.
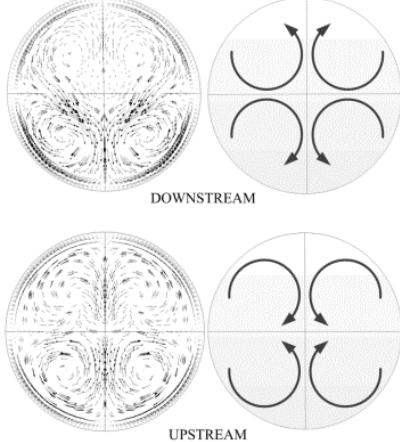

Fig. 10 Flow structure of the circular tube with downstream and upstream winglets. 


\subsubsection{Empirical correlation}

As the numerical results, the empirical correlations for the Nusselt number ratio and friction factor ratio for all cases are reported. The Nusselt number ratio depends on the Reynolds number, Prantdl number and blockage ratio, while the friction factor ratio depends on the Reynolds number and blockage ratio. The values form the correlations are found around $\pm 8 \%$ and $\pm 10 \%$ deviations for the Nusselt number ratio and friction factor ratio, respectively, as depicted in Figs. $22-24$ and Figs. $25-27$. The equations for $R W V G, D W V G, C W V G$ at $B R=0.1-$ $0.3, R e=100-2000, \alpha=30^{\circ}$ and $P R=1$ are presented in equations 10 - 15 for the $\mathrm{Nu} / \mathrm{Nu} u_{0}$ and in equations $16-21$ for the $f / f_{0}$ as follows; $\mathrm{Nu} / \mathrm{Nu}_{0}=0.391 \mathrm{Re}^{0.427} \operatorname{Pr}^{0.4} B R^{0.247}, R W V G$, Downstream (10)

$\mathrm{Nu} / N u_{0}=0.326 \operatorname{Re}^{0.433} \operatorname{Pr}^{0.4} B R^{0.217}, R W V G$, Upstream

$\mathrm{Nu} / \mathrm{Nu}_{0}=0.314 \mathrm{Re}^{0.425} \operatorname{Pr}^{0.4} B R^{0.229}, D W V G$, Downstream (12)

$\mathrm{Nu} / \mathrm{Nu} u_{0}=0.269 \operatorname{Re}^{0.429} \operatorname{Pr}^{0.4} B R^{0.191}$, DWVG, Upstream

$\mathrm{Nu} / \mathrm{Nu}_{0}=0.360 \mathrm{Re}^{0.419} \operatorname{Pr}^{0.4} B R^{0.224}, C W V G$, Downstream (14)

$\mathrm{Nu} / \mathrm{Nu} u_{0}=0.307 \mathrm{Re}^{0.423} \operatorname{Pr}^{0.4} B R^{0.193}, C W V G$, Upstream

$f / f_{0}=1.155 \mathrm{Re}^{0.385} B R^{0.393}, R W V G$, Downstream

$f / f_{0}=1.113 \operatorname{Re}^{0.391} B R^{0.393}, R W V G$, Upstream

$f / f_{0}=0.843 \operatorname{Re}^{0.342} B R^{0.184}, D W V G$, Downstream

$f / f_{0}=0.787 \operatorname{Re}^{0.359} B R^{0.197}, D W V G$, Upstream

$f / f_{0}=0.998 \mathrm{Re}^{0.366} B R^{0.305}, C W V G$, Downstream

$f / f_{0}=0.944 \operatorname{Re}^{0.377} B R^{0.306}, C W V G$, Upstream
The numerical studies on flow structure, heat transfer characteristics and thermal performance in the tube heat exchanger inserted with various types of winglet vortex generators; rectangular winglet vortex generators $(R W V G)$, delta winglet vortex generators $(D W V G)$ and curve winglet vortex generators $(C W V G)$ are examined. The influences of the blockage ratios; $b / D, B R=0.1-0.3$, flow directions; downstream and upstream and Reynolds number; $R e=100-2000$, are reported. The numerical results are presented in terms of flow structure and heat transfer behavior and compared with the smooth tube. The major findings are as follows:

The use of the winglet vortex generators can improve heat transfer rate in the test tube higher than the smooth tube for all cases. The enhancement of heat transfer rate is due to the vortex flows through the test section and the impinging flow on the tube wall. The vortex flow and impinging flow help to improve the fluid mixing between the main of the vortex flow and near the tube wall regime.

The rise of $B R$ leads to increase heat transfer rates and friction loss for all types of the winglets. The $B R=0.3$ performs highest values, while the $B R=0.1$ gives the inverted result. This is because the reduction of the flow area effects for enhancing vortex strength or vortex intensity. The strength of the vortex flow is a key for heat transfer enhancement.

The $R W V G$ gives highest heat transfer rate, while the $C W V G$ provides higher heat transfer rate than the $D W V G$. The reason of this may be that the $R W V G$ can create the strongest vortex flow through the test section, while the $D W V G$ produces the reversed trend. The $R W V G$ not only gives the highest heat transfer rate, but also provides the highest friction loss.

The downstream case shows a higher heat transfer rate than the upstream case, but performs nearly values of friction loss.

The use of all generators gives higher TEF than the smooth tube (TEF>1). In range investigations, the optimal TEF is around 2.52 at $B R$ $=0.2, R e=1000$, downstream for $R W V G$. The enhancements of heat transfer and friction factor are around $1.3-6.2$ times and $3-16$ times over the smooth tube, respectively.

\subsection{Conclusion}

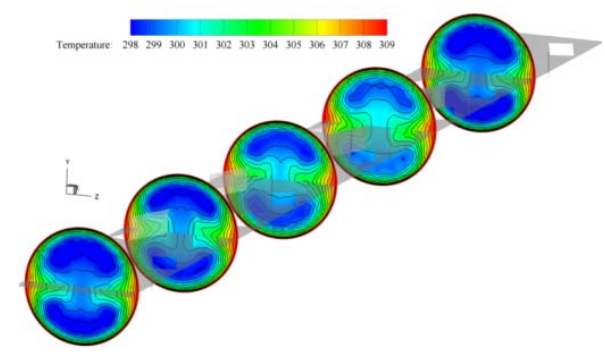

(a)

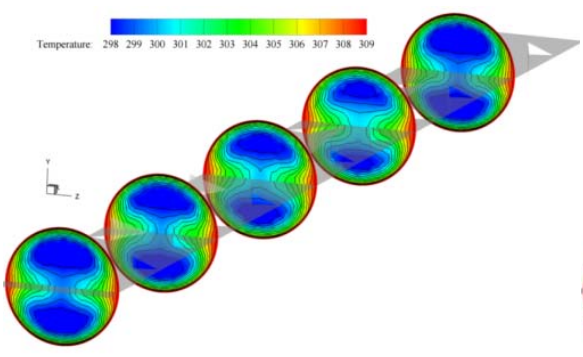

(b)

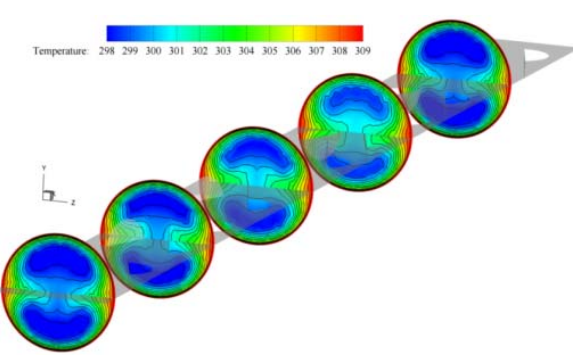

(c)

Fig. 11 Temperature distributions in transverse planes for the circular tube heat exchanger of (a) $R W V G$, (b) $D W V G$ and (c) $C W V G$ at $B R=0.2$, $R e=$ 1000 and downstream.

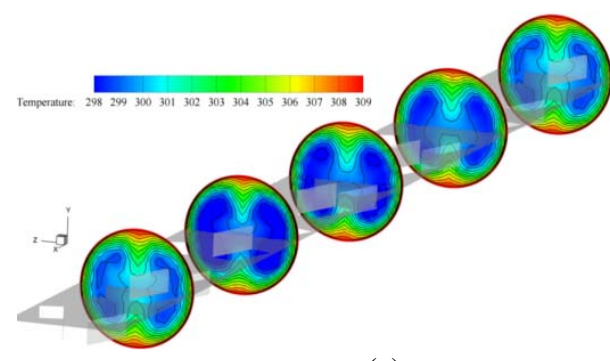

(a)

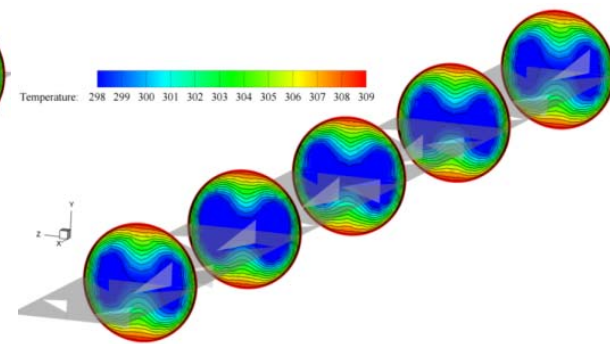

(b)

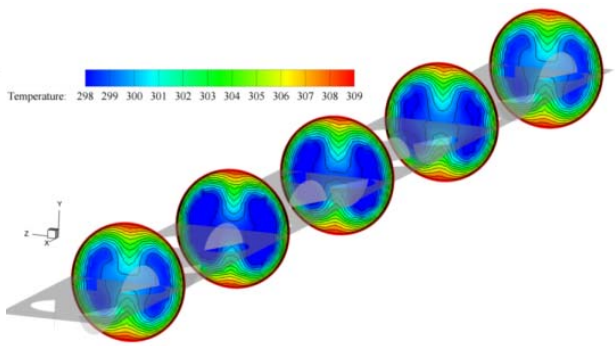

(c)

Fig. 12 Temperature distributions in transverse planes for the circular tube heat exchanger of (a) $R W V G$, (b) $D W V G$ and (c) $C W V G$ at $B R=0.2, R e=$ 1000 and upstream. 


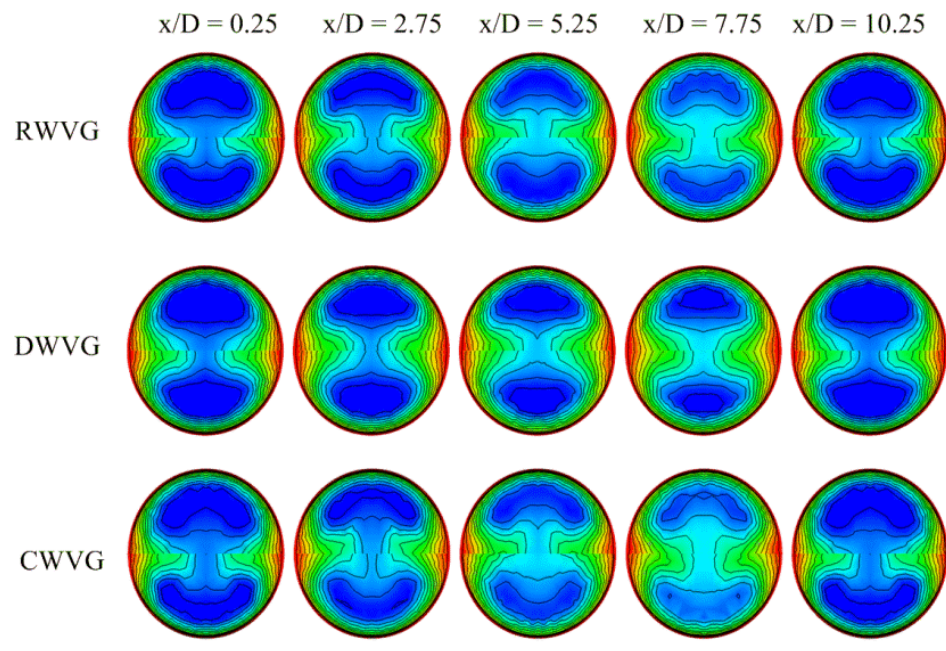

DOWNSTREAM

(a)

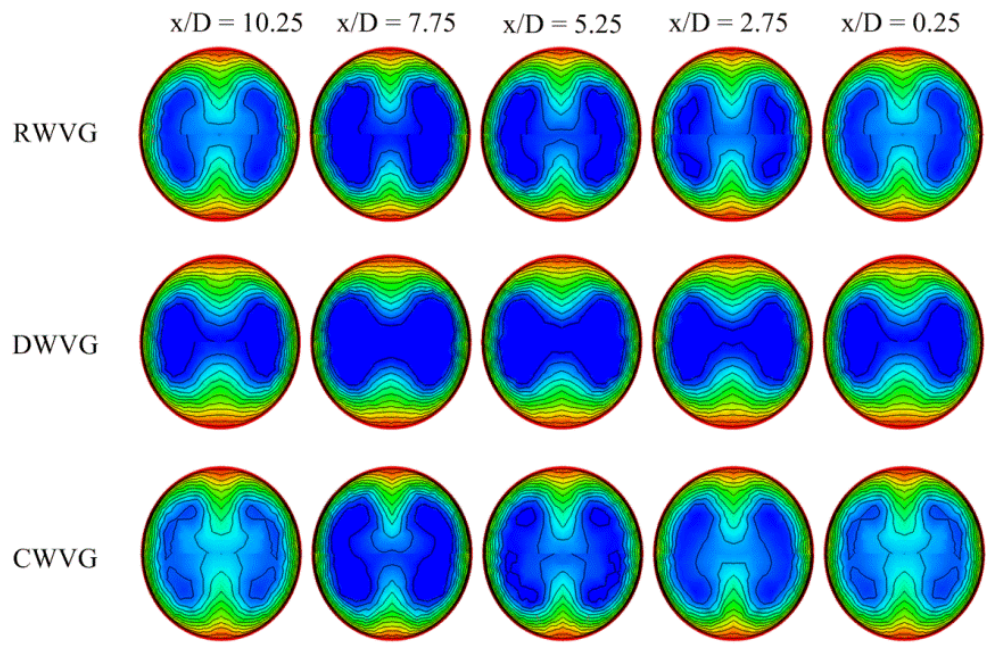

UPSTREAM

(b)

Fig. 13 Details of temperature distributions in transverse planes for (a) downstream and (b) upstream.

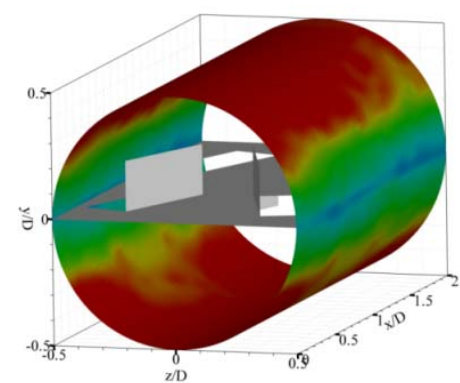

(a)
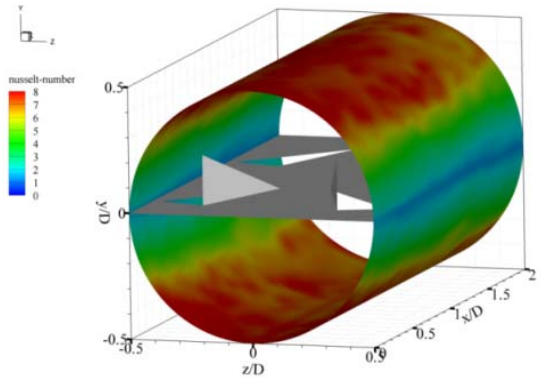

(b)

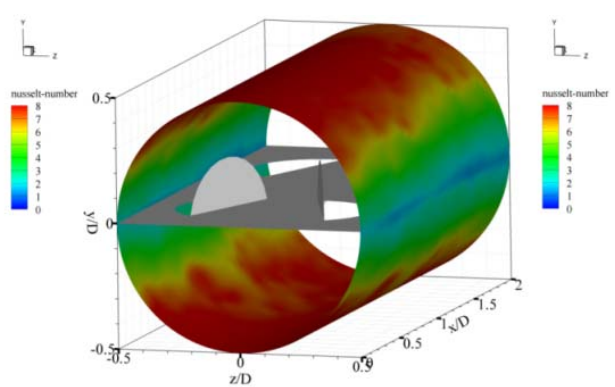

(c)

Fig. 14 Local Nusselt number distributions in transverse planes for the circular tube heat exchanger of (a) $R W V G$, (b) $D W V G$ and (c) $C W V G$ at $B R=$ $0.2, R e=1000$ and downstream. 


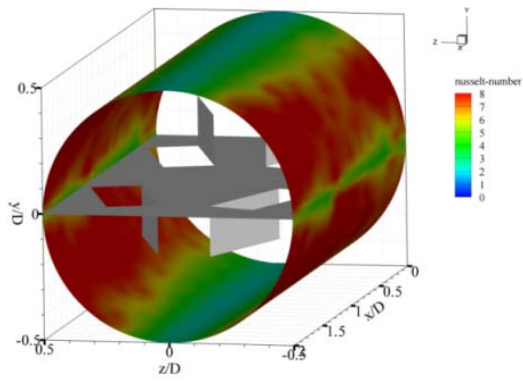

(a)

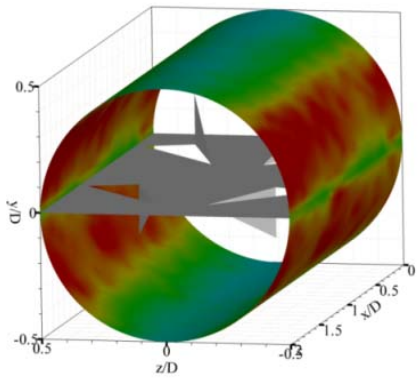

(b)

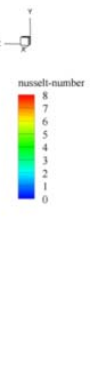

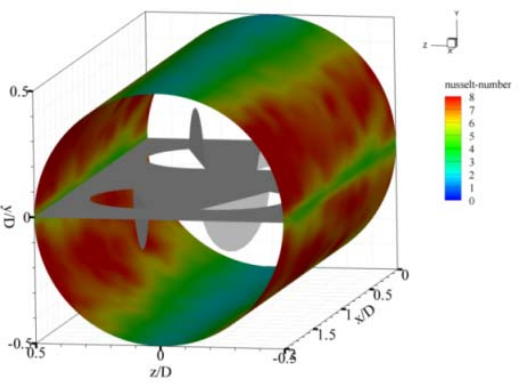

(c)

Fig. 15 Local Nusselt number distributions in transverse planes for the circular tube heat exchanger of (a) $R W V G$, (b) $D W V G$ and (c) $C W V G$ at $B R=$ $0.2, R e=1000$ and upstream.

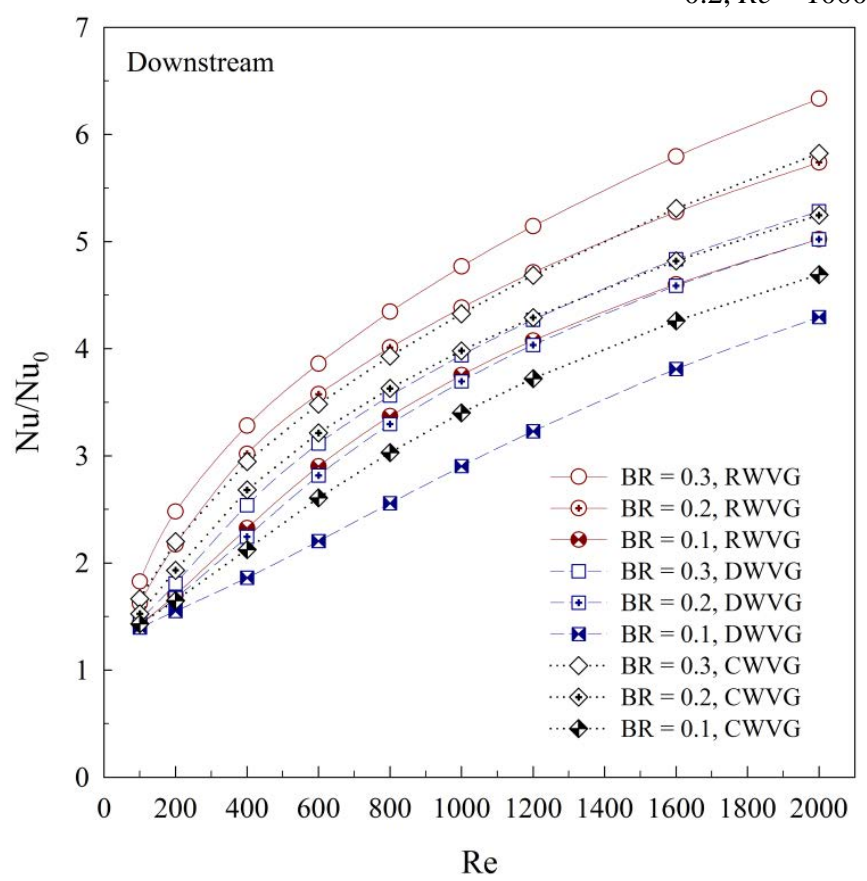

(a)

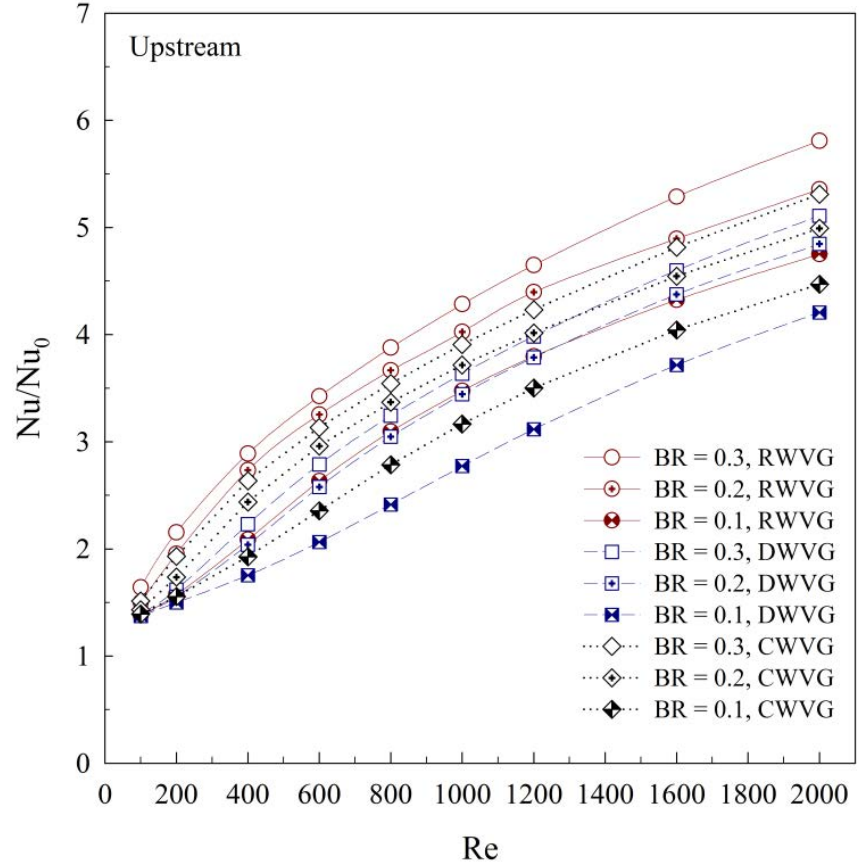

(b)

Fig. 16 Variations of the $\mathrm{Nu} / \mathrm{Nu} u_{0}$ with Reynolds number at various $\mathrm{BRs}$ for (a) downstream and (b) upstream.

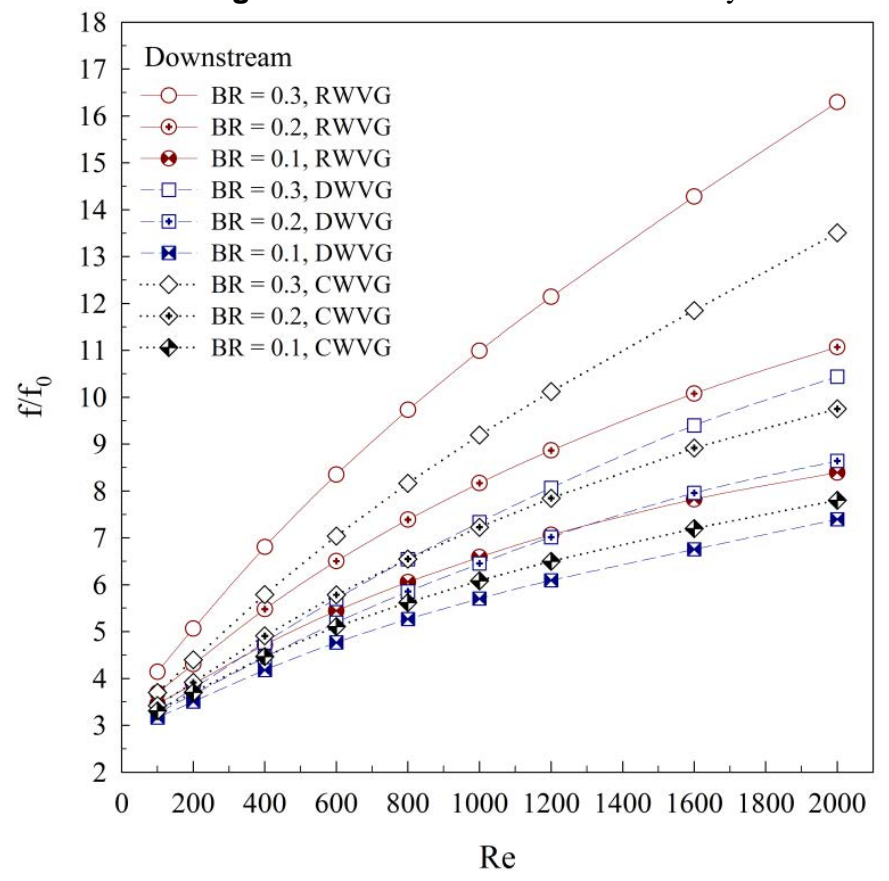

(a)

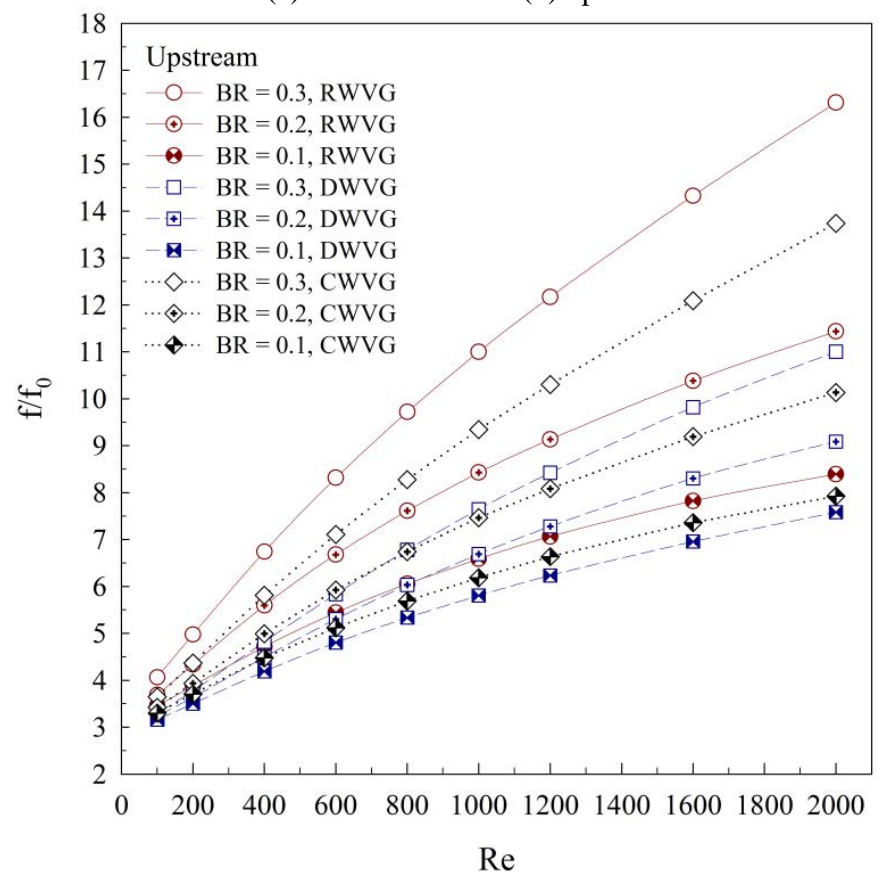

(b)

Fig. 17 Variations of the $f / f_{0}$ with Reynolds number at various $B R$ s for (a) downstream and (b) upstream. 


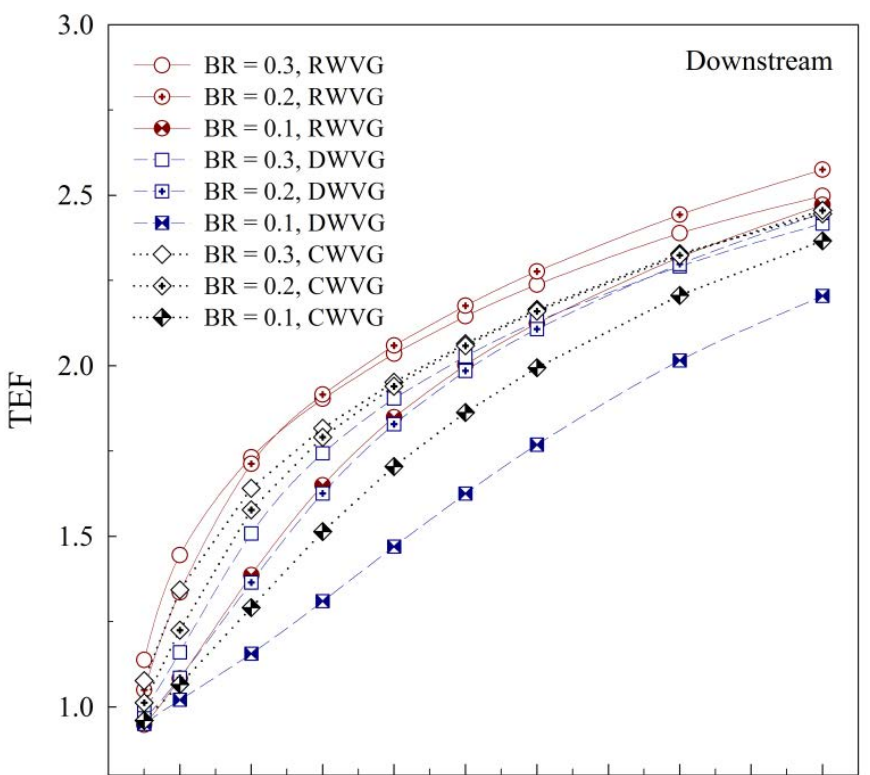

$\begin{array}{lllllllllll}0 & 200 & 400 & 600 & 800 & 1000 & 1200 & 1400 & 1600 & 1800 & 2000\end{array}$

$\operatorname{Re}$

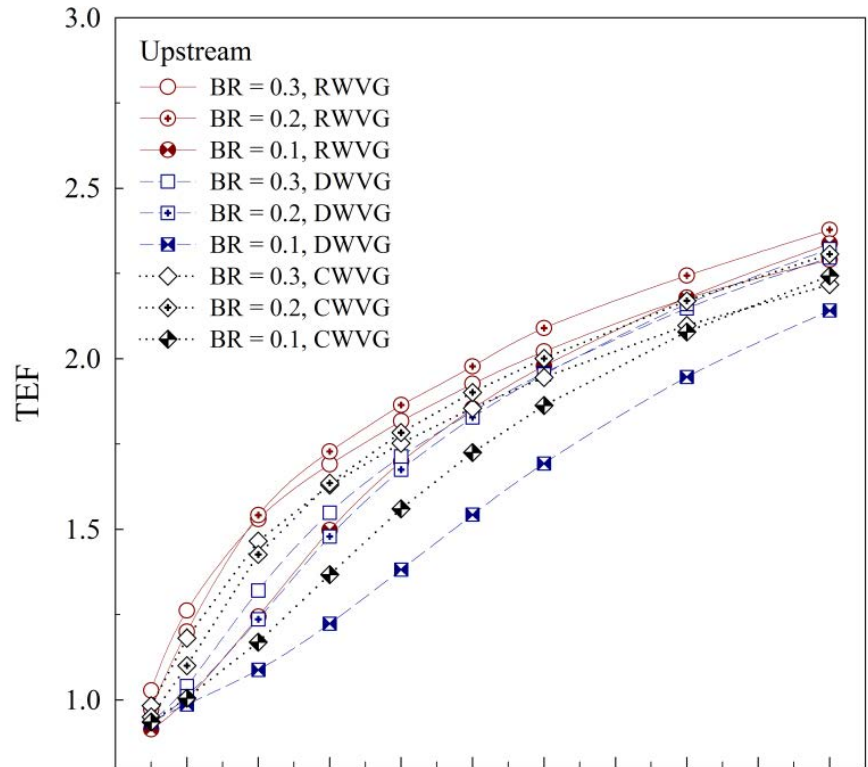

$\begin{array}{lllllllllll}0 & 200 & 400 & 600 & 800 & 1000 & 1200 & 1400 & 1600 & 1800 & 2000\end{array}$

$\operatorname{Re}$

(b)

Fig. 18 Variations of the TEF with Reynolds number at various BRs for (a) downstream and (b) upstream.

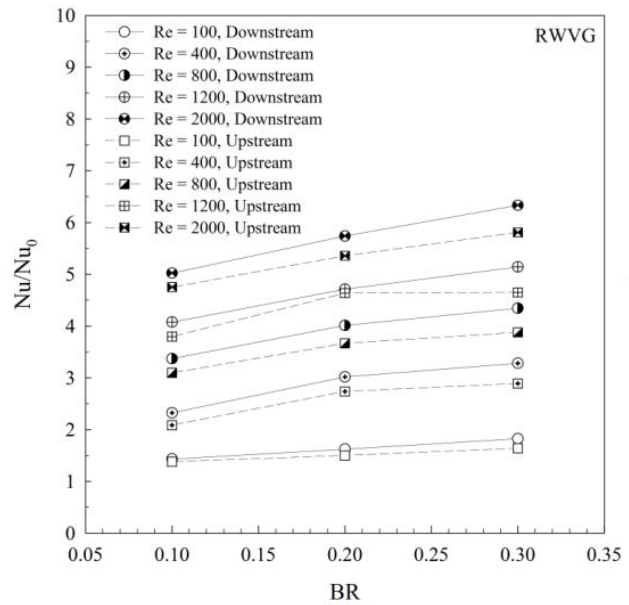

(a)

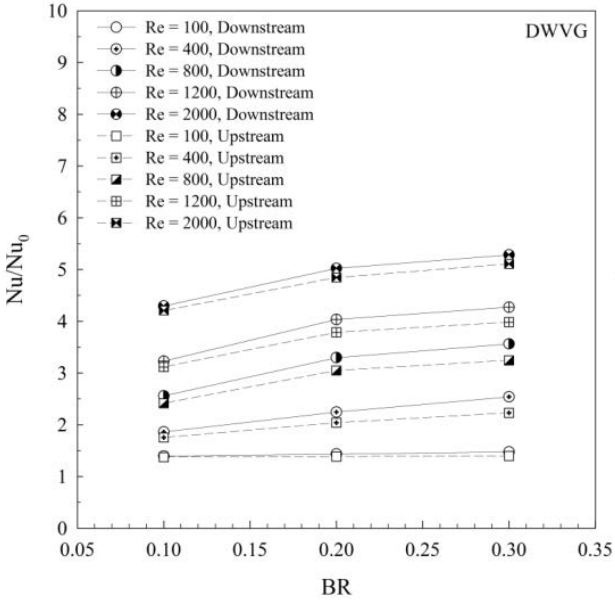

(b)

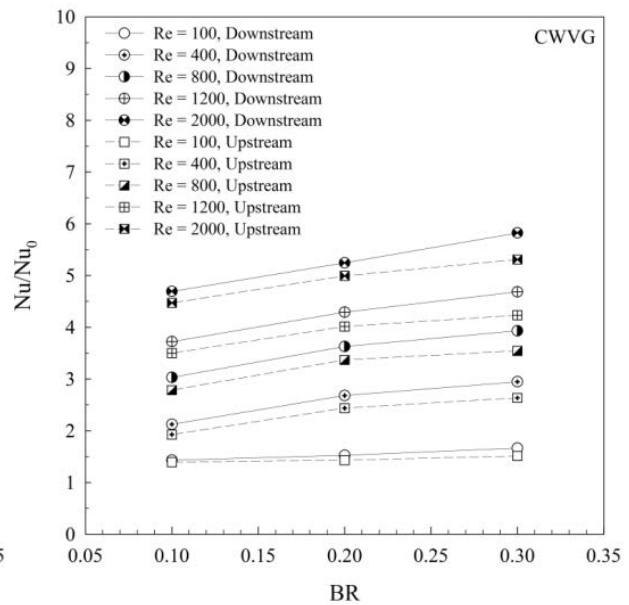

(c)

Fig. 19 Relations of the $N u / N u_{0}$ with $B R$ at various Reynolds numbers for (a) $R W V G$, (b) $D W V G$ and (c) $C W V G$.

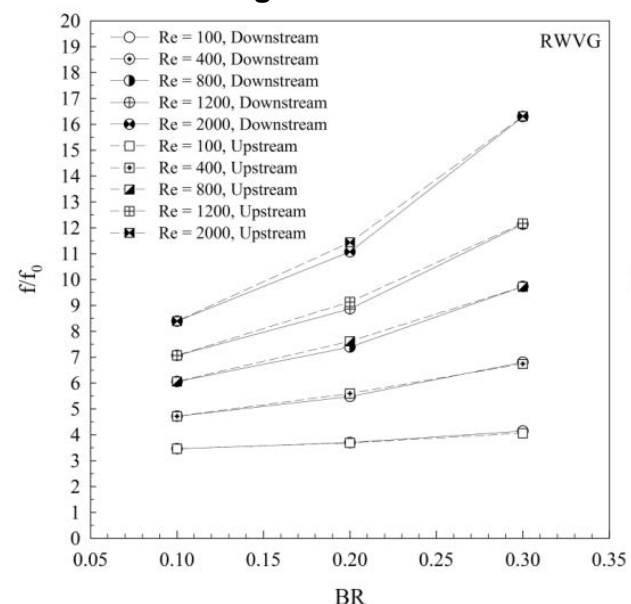

(a)

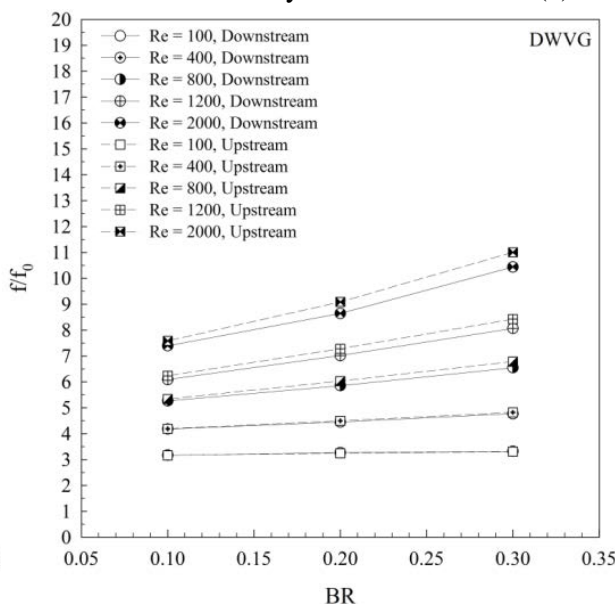

(b)

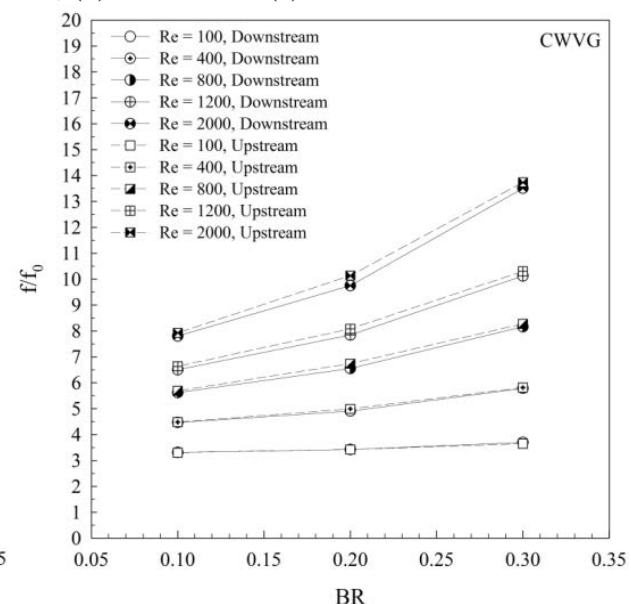

(c)

Fig. 20 Relations of the $f / f_{0}$ with $B R$ at various Reynolds numbers for (a) $R W V G$, (b) $D W V G$ and (c) $C W V G$. 


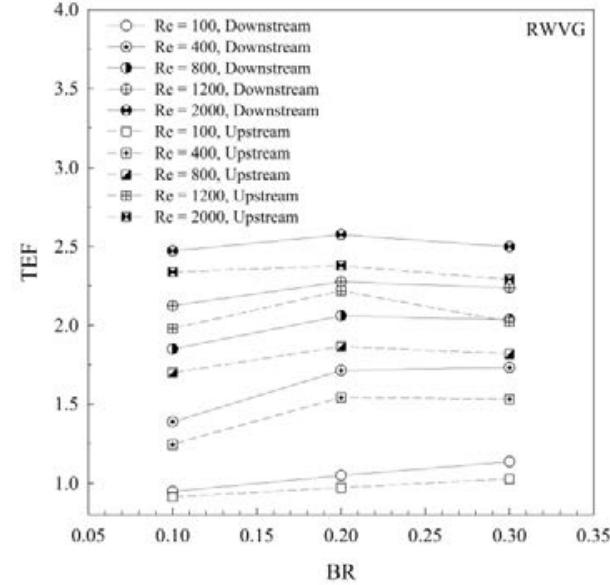

(a)

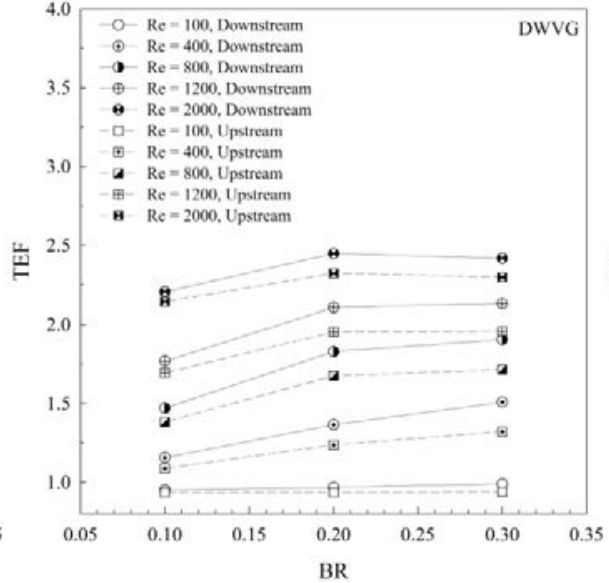

(b)

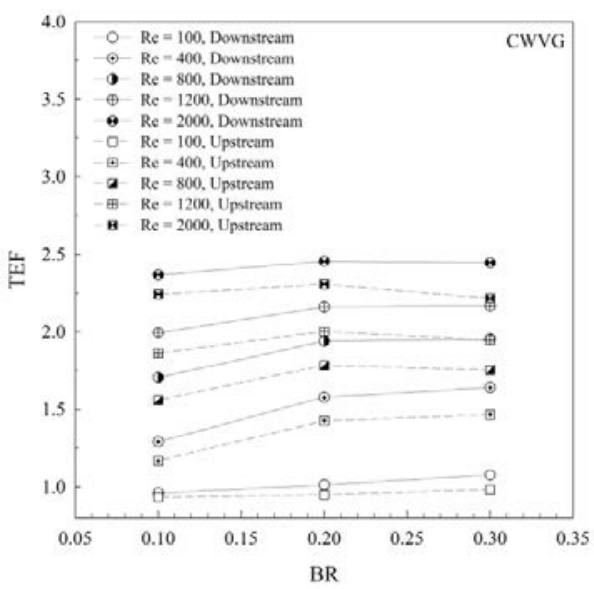

(c)

Fig. 21 Relations of the TEF with $B R$ at various Reynolds numbers for (a) $R W V G$, (b) DWVG and (c) CWVG.

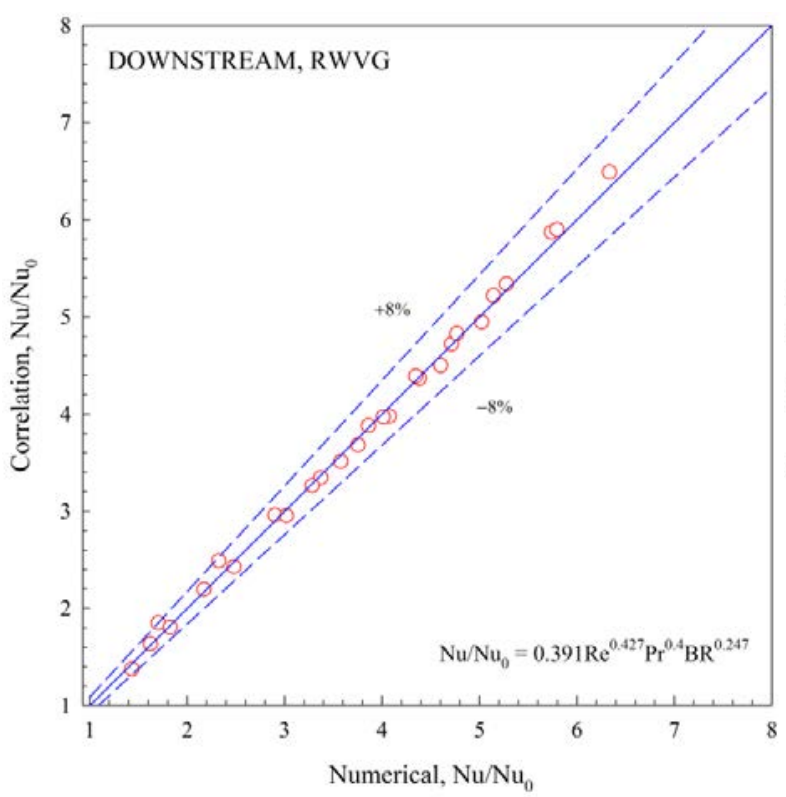

(a)

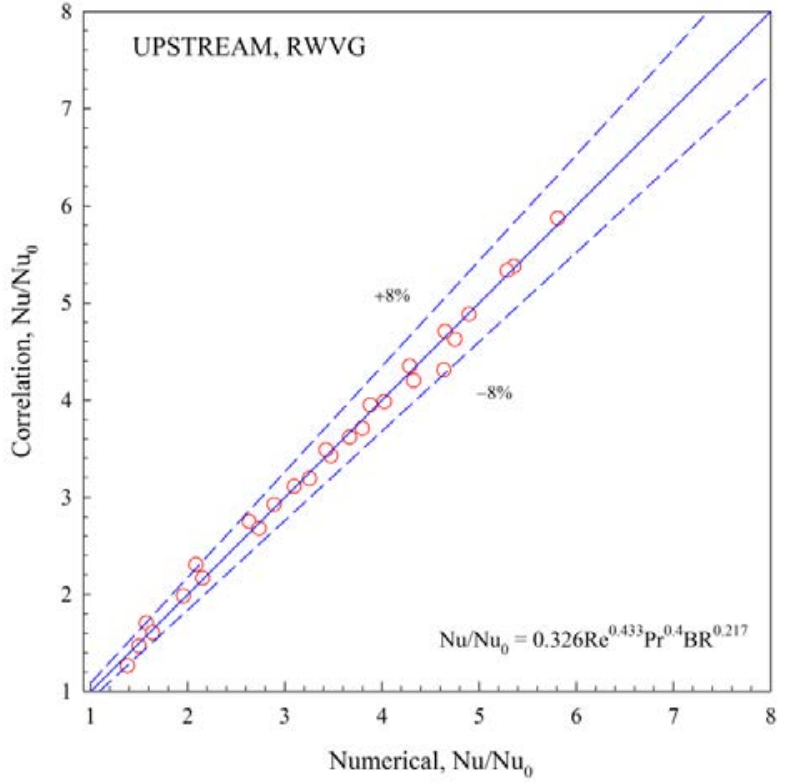

(b)

Fig. 22 Correlation of $\mathrm{Nu} / \mathrm{Nu} u_{0}$ for $R W V G$ of (a) downstream and (b) upstream.

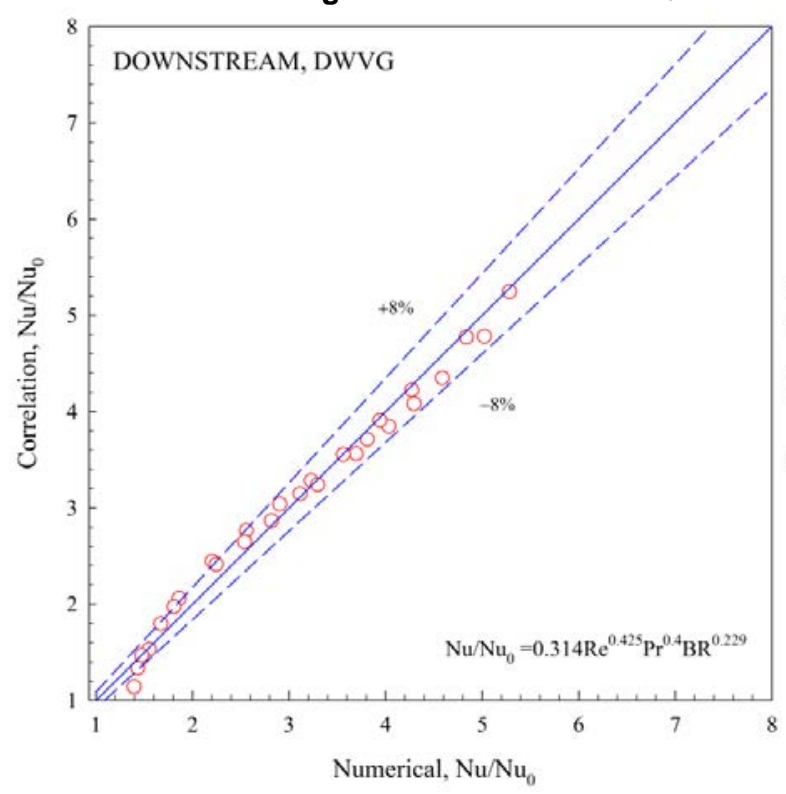

(a)

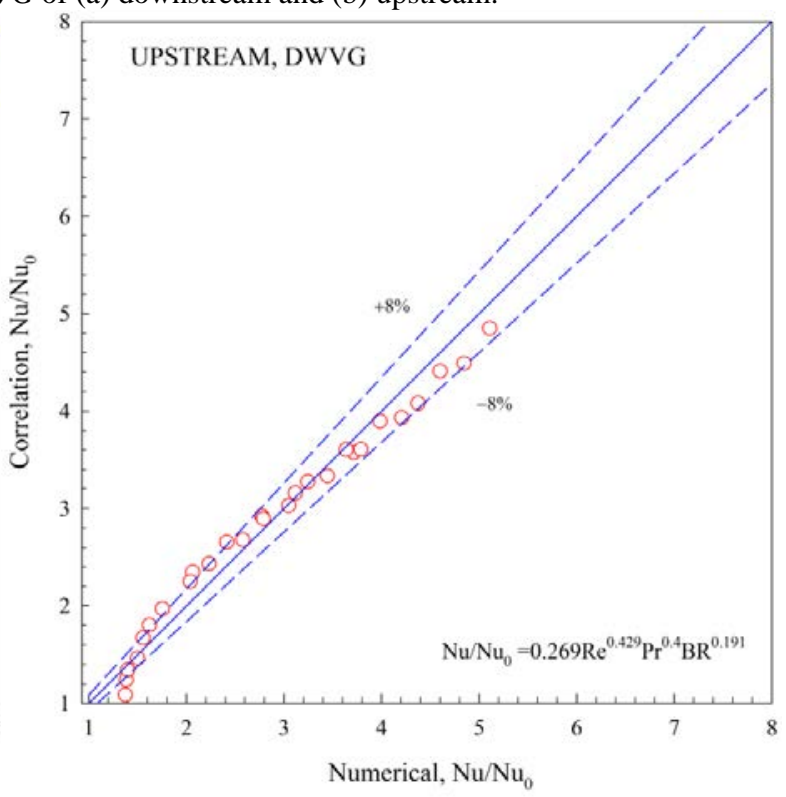

(b)

Fig. 23 Correlation of $\mathrm{Nu} / \mathrm{Nu}$ for $\mathrm{DWVG}$ of (a) downstream and (b) upstream. 


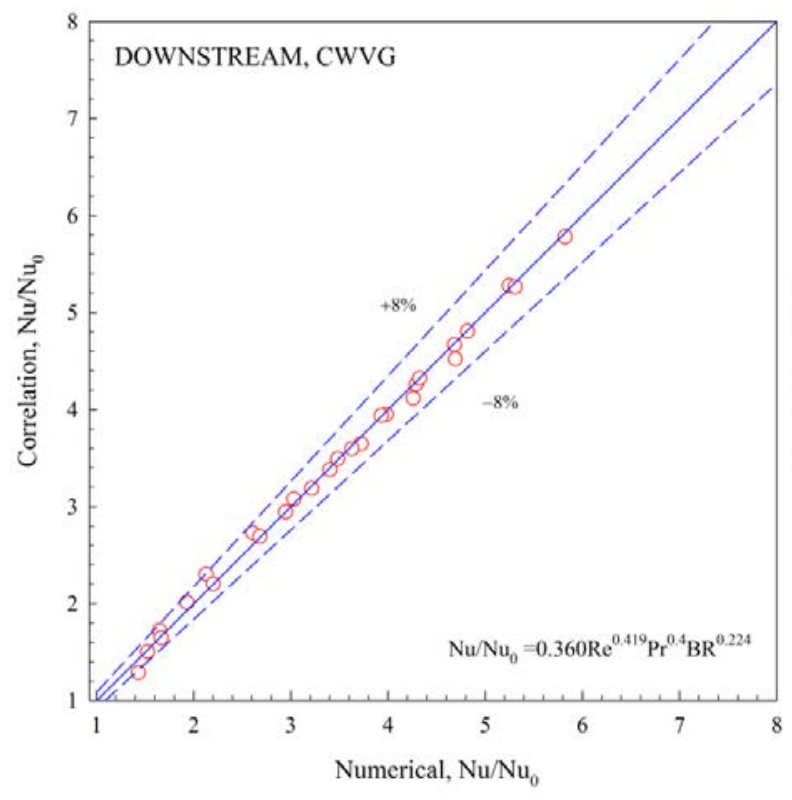

(a)

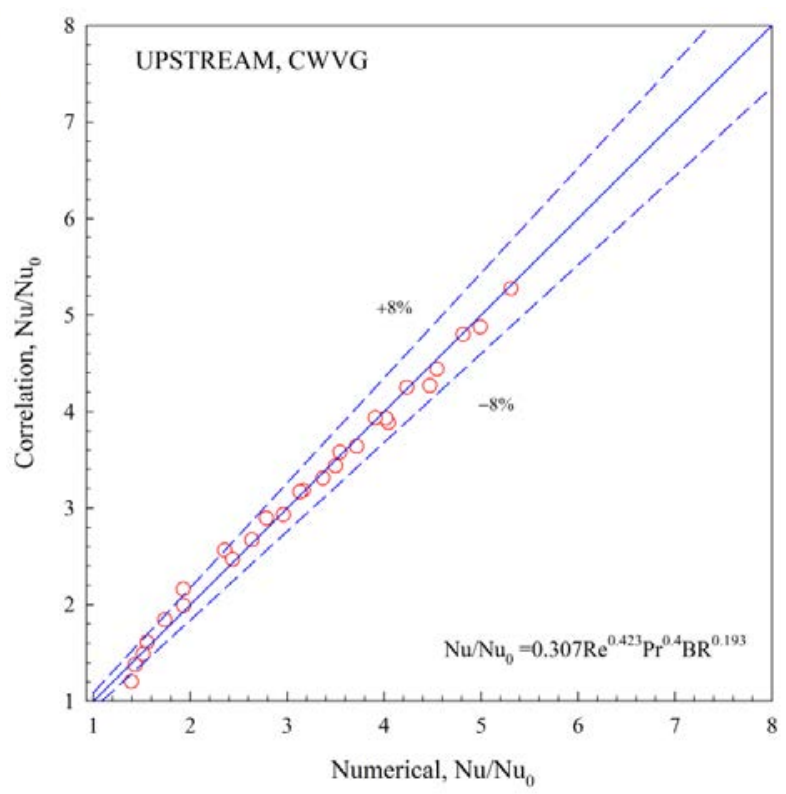

(b)

Fig. 24 Correlation of $N u / N u_{0}$ for $C W V G$ of (a) downstream and (b) upstream.

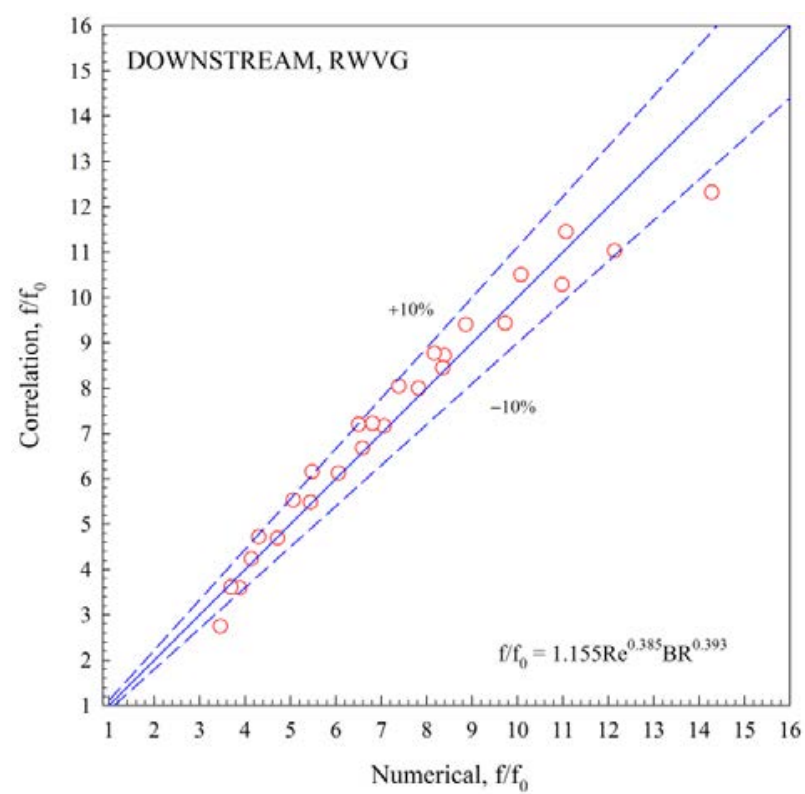

(a)

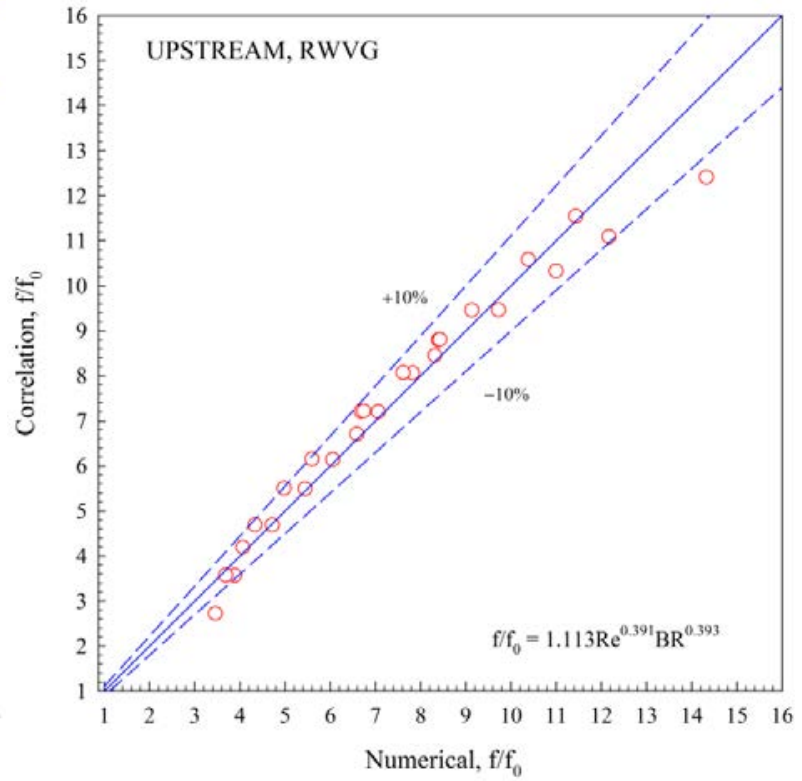

(b)

Fig. 25 Correlation of $f / f_{0}$ for $R W V G$ of (a) downstream and (b) upstream. 


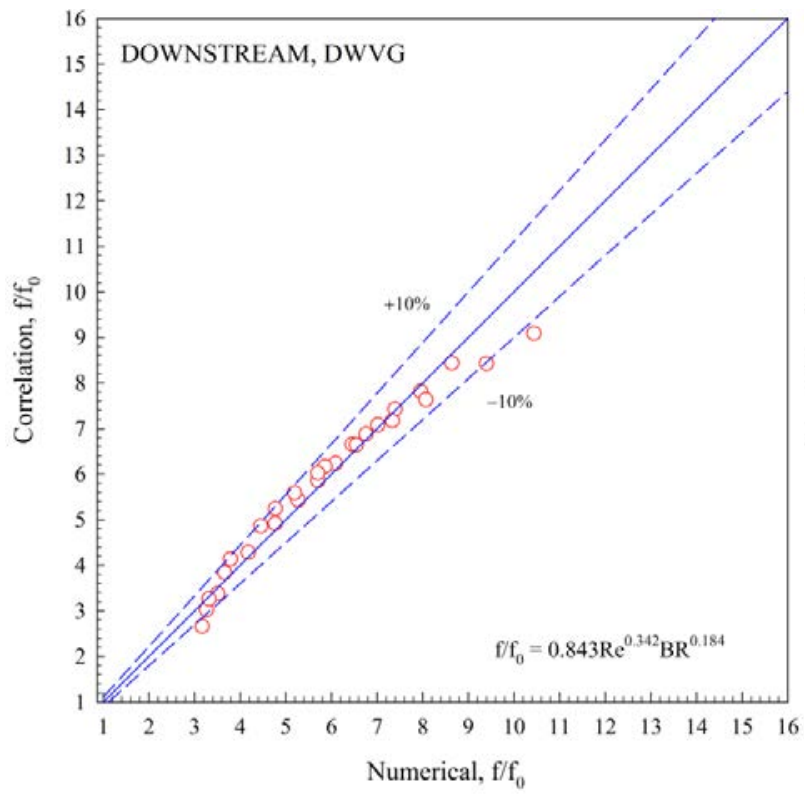

(a)

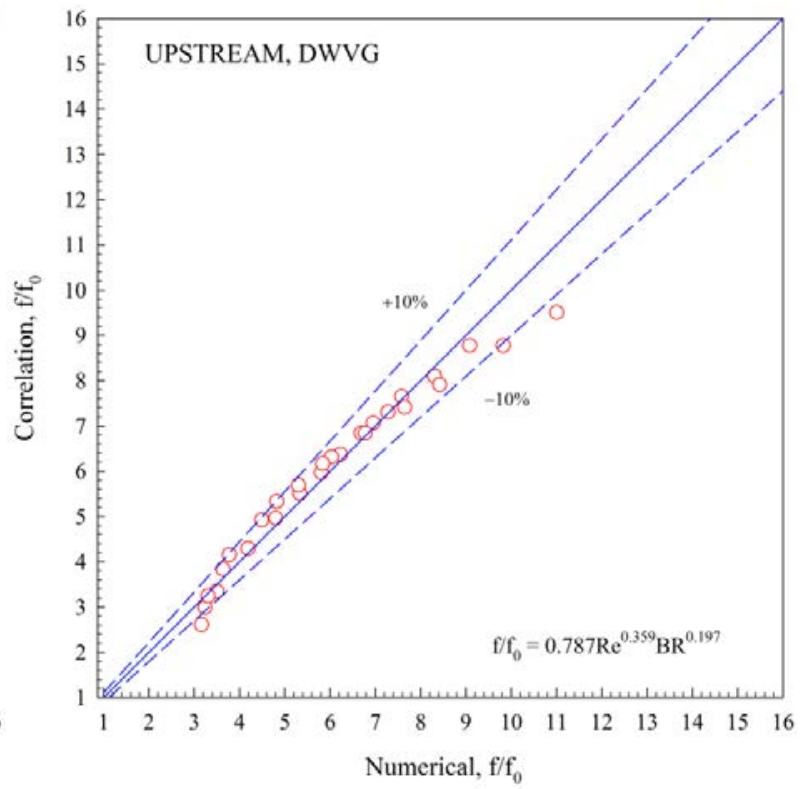

(b)

Fig. 26 Correlation of $f / f_{0}$ for $D W V G$ of (a) downstream and (b) upstream.

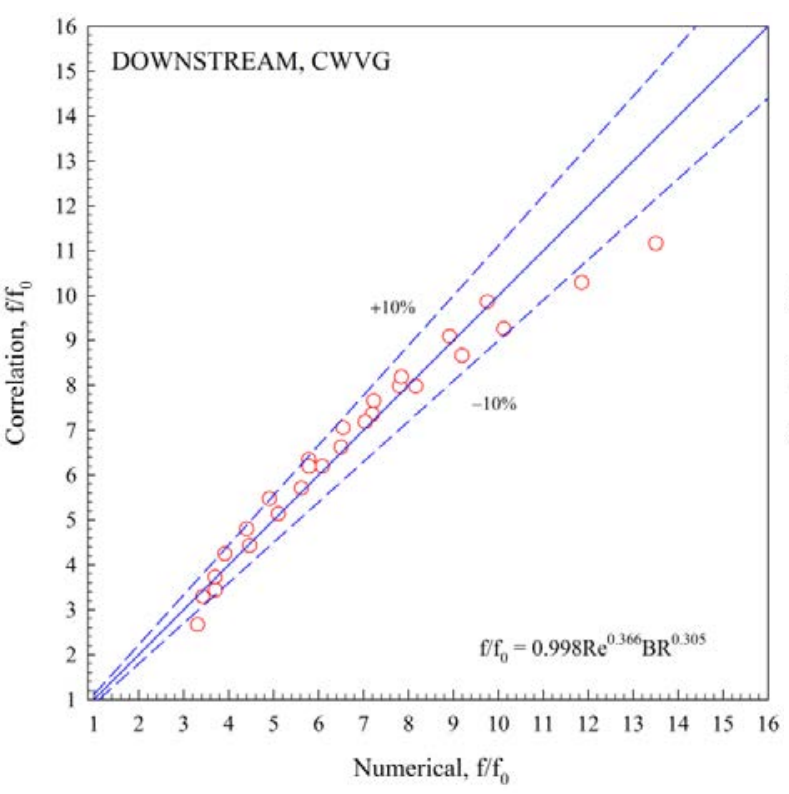

(a)

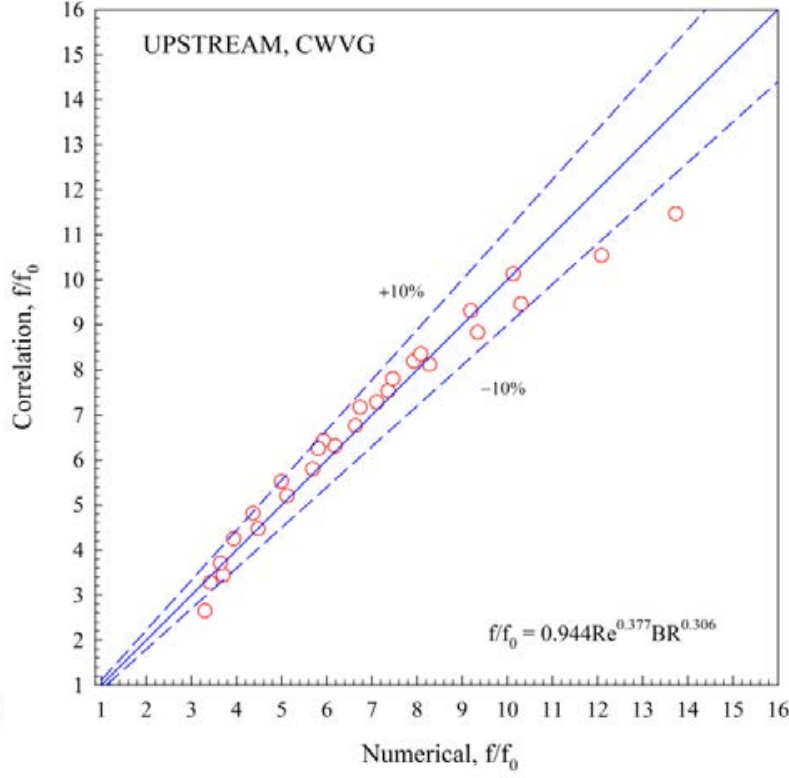

(b)

Fig. 27 Correlation of $f / f_{0}$ for $C W V G$ of (a) downstream and (b) upstream.

\section{Acknowledgement}

The funding of this work is supported by King Mongkut's Institute of Technology Ladkrabang research funds and College of Industrial Technology, King Mongkut's University of Technology North Bangkok, Bangkok, Thailand. The authors would like to thank Assoc. Prof. Dr. Pongjet Promvonge, KMITL for suggestions.

\section{Nomenclature}

$b$

D

$f$

GCI

$h$

k

$L$

$\mathrm{Nu}$

$p$ winglet height, $\mathrm{m}$

diameter of a circular tube, $\mathrm{m}$

friction factor

grid convergence index

convective heat transfer coefficient, $\mathrm{W} \mathrm{m} \mathrm{m}^{-2} \mathrm{~K}^{-1}$

thermal conductivity, $\mathrm{W} \mathrm{m}^{-1} \mathrm{~K}^{-1}$

spacing between winglet, $\mathrm{m}$

Nusselt number

static pressure, $\mathrm{Pa}$
$\operatorname{Pr}$

$P R$

Re

$T$

$u_{\mathrm{i}}$

$u_{\mathrm{m}}$

Greek letter

$\mu$

$\Gamma$

$\alpha$

TEF

$\rho$

Subscript

in inlet

0 smooth tube
Prandtl number

Pitch spacing ratio

Reynolds number temperature, $\mathrm{K}$ velocity in $\mathrm{x}_{\mathrm{i}}$-direction, $\mathrm{m} \mathrm{s}^{-1}$ mean velocity in channel, $\mathrm{m} \mathrm{s}^{-1}$

dynamic viscosity, $\mathrm{kg} \mathrm{s}^{-1} \mathrm{~m}^{-1}$

thermal diffusivity

flow attack angle, degree

thermal enhancement factor, $\left(=\left(N u / N u_{0}\right) /\left(f / f_{0}\right)^{1 / 3}\right)$

density, $\mathrm{kg} \mathrm{m}^{-3}$ 


$\begin{array}{ll}\text { w } & \text { wall } \\ \text { pp } & \text { pumping power }\end{array}$

\section{REFERENCES}

Aliabadi, M.K., Sartipzadeh, O. and Alizadeh, A., 2015, “An Experimental Study on Vortex-generator Insert with Different Arrangements of Delta-winglets,” Energy, 82, 629-639. http://dx.doi.org/10.1016/j.energy.2015.01.072

Caliskan, S., 2014, "Experimental Investigation of Heat Transfer in a Channel with New Winglet-type Vortex Generators,” International Journal of Heat and Mass Transfer, 78, 604-614. http://dx.doi.org/10.1016/j.ijheatmasstransfer.2014.07.043

Chokphoemphun, S., Pimsarn, M., Thianpong, C. and Promvonge, P. 2015, "Heat Transfer Augmentation in A Circular Tube with Winglet Vortex Generators," Chinese Journal of Chemical Engineering, 23(4), 605-614.

http://dx.doi.org/10.1016/j.cjche.2014.04.002

Hatami, M., Ganji, D.D. and Bandpy, M.G., 2015, "Experimental Investigations of Diesel Exhaust Exergy Recovery using Delta Winglet Vortex Generator Heat Exchanger,” International Journal of Thermal Sciences, 93, 52-63.

http://dx.doi.org/10.1016/j.ijthermalsci.2015.02.004

Hsiao, K.Y., Wu, C.Y. and Huang, Y.T., 2014, "Fluid Mixing in A Microchannel with Longitudinal Vortex Generators," Chemical Engineering Journal, 235, 27-36.

http://dx.doi.org/10.1016/j.cej.2013.09.010

Incropera, F., and Dewitt, P.D., 2006, Introduction to Heat Transfer, $5^{\text {rd }}$ ed., John Wiley \& Sons, Hoboken, NJ.

Li, L., Du, X., Zhang, Y., Yang, L. and Yang, Y., 2015, "Numerical Simulation on Flow and Heat transfer of Fin-and-tube Heat Exchanger with Longitudinal Vortex Generators," International Journal of Thermal Sciences, 92, 85-96.

http://dx.doi.org/10.1016/j.ijthermalsci.2015.01.030

Lin, Z.M., Liu, C.P., Lin, M. and Wang, L.B., 2015, “Numerical Study of Flow and Heat Transfer Enhancement of Circular Tube Bank Fin Heat Exchanger with Curved Delta-winglet Vortex Generators,” Applied Thermal Engineering, 88, 198-210. http://dx.doi.org/10.1016/j.applthermaleng.2014.11.079

Lotfi, B., Zeng, M., Sundén, B. and Wang, Q., 2014a, “3D Numerical Investigation of Flow and Heat Transfer Characteristics in Smooth Wavy Fin-and-Elliptical Tube Heat Exchangers using New Type Vortex Generators,” Energy, 73, 233-257.

http://dx.doi.org/10.1016/j.energy.2014.06.016

Lotfi, B., Zeng, M., Sundén, B. and Wang, Q., 2014b, “Thermohydraulic Characterization of The Smooth Wavy Fin-and-elliptical Tube Heat Exchangers Using New Type Vortex Generators," Energy Procedia, 61, 2343-2346.

http://dx.doi.org/10.1016/j.egypro.2014.11.1199
Delač, B., Trp, A. and Lenić, K., 2014, “Numerical Investigation of Heat Transfer Enhancement in A Fin and Tube Heat Exchanger using Vortex Generators," International Journal of Heat and Mass Transfer, 78, 662669.

http://dx.doi.org/10.1016/j.ijheatmasstransfer.2014.07.027

Du, X., Feng, L., Li, L., Yang, L. and Yang, Y., 2014, “Heat Transfer Enhancement of Wavy Finned Flat Tube by Punched Longitudinal Vortex Generators,” International Journal of Heat and Mass Transfer, 75, 368-380.

http://dx.doi.org/10.1016/j.ijheatmasstransfer.2014.03.081

Gholami, A.A., Wahid, M.A. and Mohammed, H.A., 2014, "Heat Transfer Enhancement and Pressure Drop for Fin-and-Tube Compact Heat Exchangers with Wavy Rectangular Winglet-type Vortex Generators," International Communications in Heat and Mass Transfer, 54, 132-140.

http://dx.doi.org/10.1016/j.icheatmasstransfer.2014.02.016

Gong, B., Wang, L.B. and Lin, Z.M., 2015, “Heat Transfer Characteristics of A Circular Tube Bank Fin Heat Exchanger with Fins Punched Curve Rectangular Vortex Generators in The Wake Regions of The Tubes," Applied Thermal Engineering, 75, 224-238. http://dx.doi.org/10.1016/j.applthermaleng.2014.09.043

Min, J. and Zhang, B., 2014, "Numerical Studies of Convective Mass Transfer Enhancement in A Membrane Channel by Rectangular Winglets,” Chinese Journal of Chemical Engineering, 22(10), 10611071.

http://dx.doi.org/10.1016/j.cjche.2014.09.004

Patankar, S.V., 1980, Numerical Heat Transfer and Fluid Flow, McGraw-Hill, New York.

Saha, P., Biswas, G. and Sarkar, S., 2014, “Comparison of Winglet-type Vortex Generators Periodically Deployed in A Plate-fin Heat Exchanger - A synergy based analysis," International Journal of Heat and Mass Transfer, 74, 292-305. http://dx.doi.org/10.1016/j.ijheatmasstransfer.2014.03.015

Wang, W., Bao, Y. and Wang, Y., 2015, "Numerical Investigation of A Finned-tube Heat Exchanger with Novel Longitudinal Vortex Generators,” Applied Thermal Engineering, 86, 27-34.

http://dx.doi.org/10.1016/j.applthermaleng.2015.04.041

Wang, Y., He, Y.L., Yang, W.W. and Cheng, Z.D., 2015, “Numerical Analysis of Flow Resistance and Heat Transfer in A Channel with Delta Winglets under Laminar Pulsating Flow," International Journal of Heat and Mass Transfer, 82, 51-65.

http://dx.doi.org/10.1016/j.ijheatmasstransfer.2014.11.016

Zdanski, P.S.B., Pauli, D. and Dauner, F.A.L., 2015, “Effects of Delta Winglet Vortex Generators on Flow of Air over In-line Tube Bank: A New Empirical Correlation for Heat Transfer Prediction,” International Communications in Heat and Mass Transfer, 67, 89-96. http://dx.doi.org/10.1016/j.icheatmasstransfer.2015.07.010

Zhou, G. and Feng, Z., 2014, "Experimental Investigations of Heat Transfer Enhancement by Plane and Curved Winglet Type Vortex Generators with Punched Holes," International Journal of Thermal Sciences, 78, 26-35.

http://dx.doi.org/10.1016/j.ijthermalsci.2013.11.010 